\title{
GEOQUÍMICA DA ALTERAÇÃO SUPÉRGENA DAS ROCHAS ULTRAMÁFICAS DE SANTA FÉ (GOIÁS, BRASIL)*
}

\author{
SÔNIA MARIA BARROS DE OLIVEIRA** e JEAN-JACQUES TRESCASES***
}

\begin{abstract}
The nickeliferous deposit of Santa Fé (GO) is the product of the weathering of an ultramafic-alkaline massif. The landscape consists of lowlands (Velhas Cycle-Early Quaternary) and hills that are relicts of the South-American surface (Tertiary). Weathering profiles are thick in the lowlands with four layers: altered rocks, coarse saprolite, fine saprolite, and red laterite. Magnesian silicates evolve to goethite and then to hematite.

The geochemical evolution of the lateritic profile in the lowlands leads to leaching of $\mathrm{Si}$ and $\mathrm{Mg}$ and retention of $\mathrm{Fe}, \mathrm{Al}, \mathrm{Cr}, \mathrm{Mn}, \mathrm{Cu}$, and $\mathrm{Co}$. Ni shows an intermediate behavior. Partitioning of elements among minerals is computed here for each stage of weathering. $\mathrm{Ni}$ is mainly associated with silicate phases (inherited serpentine and amorphous $\mathrm{Si}$-Fe products).

On the hills, fresh and/or silicified rocks crops out. The silicification event was related to the South American cycle and occured at the bottom of Tertiary profiles. Later, with the dismantling of the South American surface, the hills emerged capped by the silica layer. The removed weathered products were the source for the red laterite in the lowlands.

The deposit of Santa Fé is compared with other lateritic nickeliferous deposits in the world.
\end{abstract}

INTRODUÇÃo A alteração supérgena das rochas ultramáficas de Santa Fé conduziu à formação de um manto laterítico enriquecido em $\mathrm{Ni}$. $\mathrm{O}$ objetivo deste trabalho é o de caracterizar geoquimicamente as tendências atuais do intemperismo e investigar a natureza dos processos prevalecentes no passado, levando, assim, ao esclarecimento da gênese do depósito niquelífero.

\section{A. Localização $\mathrm{O}$ maciço de Santa Fé situa-se no su- doeste do Estado de Goiás, a cerca de $250 \mathrm{~km}$ a noroeste de Goiânia. Trata-se de um corpo intrusivo de forma elipsoidal com ó eixo maior na direção NS, medindo aproximadamente $9,5 \mathrm{~km}$, e o menor na direção $\mathrm{EW}$, com cerca de $6,5 \mathrm{~km}$ (área total $38 \mathrm{~km}^{2}$ ). A região per- tence ao domínio fitogeográfico do cerrado e possui cli- ma tropical úmido de inverno seco e verão chuvoso.}

B. Geologia As rochas ultramáficas de Santa Fé pertencem à família ultramáfico-alcalina (Grupo Iporá) de idade cretácea (Lessa So et al., 1971; Barbour, 1976; e Barbour et al., 1979) e são intrusivas em gnaisses relacionados ao ciclo Brasiliano. $O$ corpo intrusivo é um domo zonado de núcleo dunítico, envolvido por camadas descontinuas e concêntricas de peridotito e piroxenito (Fig. 1). Rochas alcalinas ocorrem como pequenos corpos nas zonas mais periféricas do maciço. A associação dominante é, assim, caracterizada por dunito serpentinizado, wehrlito e clinopiroxenito. Os primeiros såo as rochas mais abundantes, constituindo mais de dois terços da área aflorante $\left(26 \mathrm{~km}^{2}\right)$.

No dunito, o padrão textural é definido por um reticulado poliédrico de serpentina fibrosa (serpentina I) em duas bandas justapostas, onde as lamelas do mineral dispõem-se normalmente às paredes, e cujos centros são ocupados ou por cristais remanescentes de olivina mag. nesiana, ou por serpentina tabular (serpentina II). Cristais de cromita idiomórfica distribuem-se irregularmente por toda a rocha e são muitas vezes circundados por um mineral micáceo de natureza intermediária entre a vermiculita e a clorita. A magnetita xenomorfa dispõese entre as duas bandas de serpentina. Ainda ocorrem finas e descontínuas vênulas de carbonato e brucita disseminadas pela rocha.

No clinopiroxenito, o mineral dominante é o diopsídio, raramente serpentinizado, associado a opacos e a um filossilicato da família flogopita-vermiculita. Os wehrlitos variam em composição entre os dois extremos acima descritos.

Os três tipos litológicos apresentam-se freqüentemente recortados por veios brancos que atingem espessura de alguns milímetros, formados por carbonatos de $\mathrm{Mg}$ e Ca, associados ou não à brucita, e por serpentina bem cristalizada (serpentina III).

Do ponto de vista químico (Tab. 1), são rochas magnesianas a calco-magnesianas da seqüência sifêmica, cujá feição mais notável é a grande pobreza em álcalis e alumina.

* Trabalho realizado com auxílio da FAPESP e CNPq

** Instituto de Geociências da Universidade de São Paulo, Caixa postal 20899 - São Paulo (SP)

*** Office de la Recherche Scientifique et Technique Outre-Mer, Orstom - Paris, França / Instituto de Geociências da Universidade de São Paulo, Caixa postal 20899 - Såo Paulo (SP) 


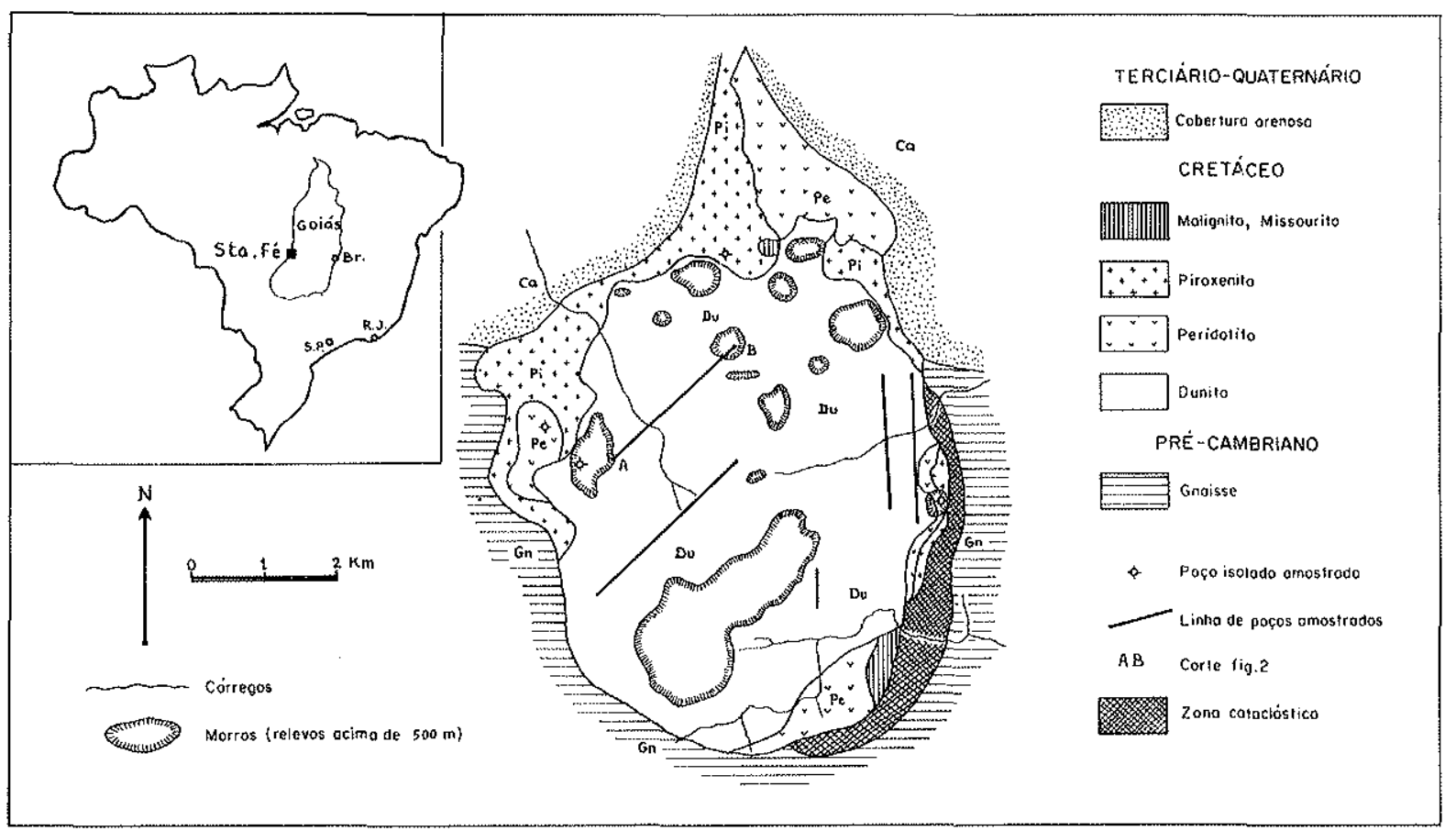

Figura 1 - O maciço de Santa Fé: localizaçăo, geologia e pontos amostrados

C. Relevo O maciço destaca-se na paisagem pelos testemunhos de erosão, constituidos por uma dezena de morrotes espalhados ao norte, e por um espigão contínuo ao sul, que emergem de uma superfície aplainada relacionada ao ciclo de erosão Velhas, do Quaternário Inferior (Figs. 1 e 2).

Nos cumes dos morrotes, de altitudes variáveis entre 500 e $570 \mathrm{~m}$, aflora a rocha quase fresca, ou intensamente silicificada. Esses relevos residuais podem ser interpretados como remanescentes da superfície sul-americana, cuja fase de agradação data do Terciário Inferior e que vem sendo desmantelada a partir do Terciário Superior (King, 1956; e Bratn, 1970).
Nos flancos dos morrotes começa a desenvolver-se um perfil de alteração que encontra sua expressão mais acabada nas baixadas. Esses sítios, a $450 \mathrm{~m}$ de altitude média, ocupam a maior parte da área do distrito ( $80 \%$ da zona dunítica e $87 \%$ do maciço) e são recobertos em toda sua extensão por uma camada de laterita vermelha concrecionar, localmente endurecida, formando crostas (canga).

D. Alteração $\mathrm{O}$ perfil de alteração típico em região de baixada, sobre dunito, compõe-se de quatro horizontes bem individualizados, desenvolvidos a partir da ro-

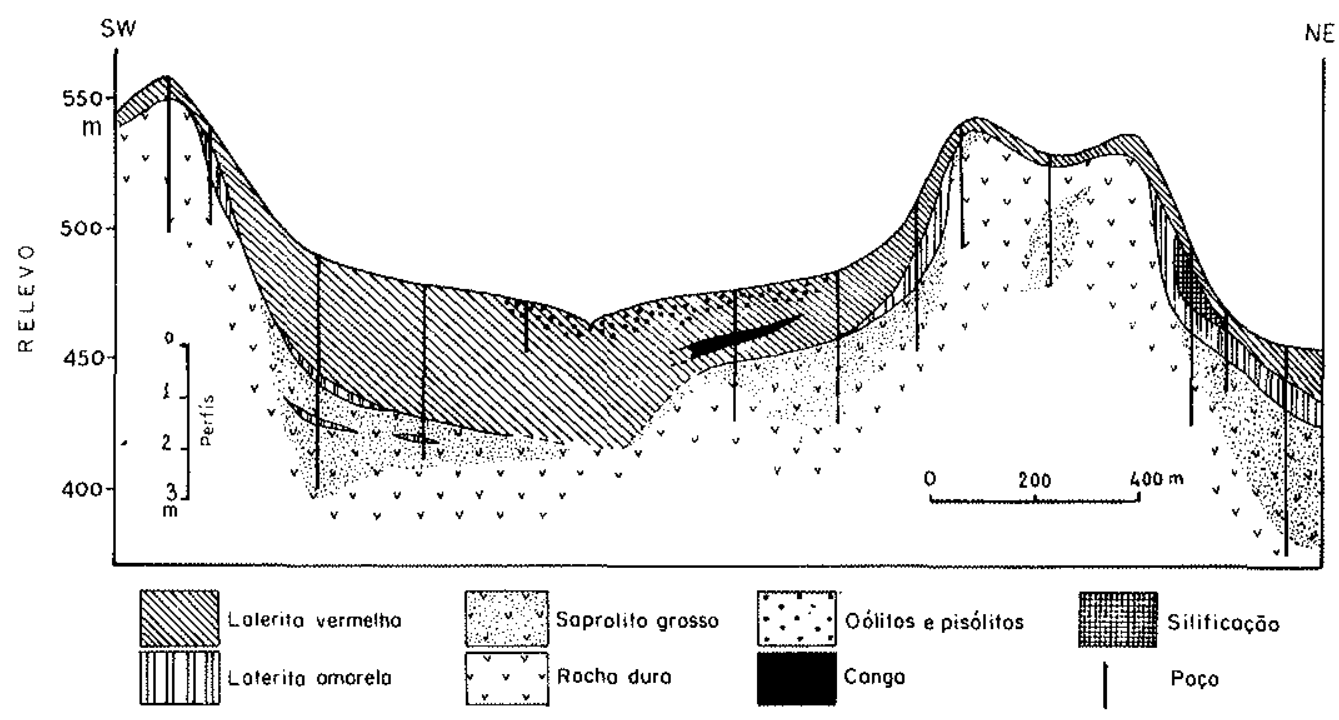

Figura 2 - Distribuição dos fácies de alteração 
cha fresca $(R)$, de verde-escura a preta de densidade 2,7 , que aparece a profundidades maiores que $20 \mathrm{~m}$ (Fig. 6A).

A rocha dura (RD) apresenta os primeiros sinais de alteração supérgena com perda do brilho, queda de densidade (de 1,7 a 2,5) e, ao nível microscópico, pela alteração da olivina por dissolução incongruente. Pode aparecer recortada por vênulas de quartzo e garnierita.

O saprolito grosso (SG) é um material rochoso marrom-amarelado, mais alterado que o anterior, de estrutura conservada e de coesão e densidade reduzidas (de 1,8 a 1,3). Possui espessura de 2 a $4 \mathrm{~m}$. Nessa fácies, a olivina desapareceu, sendo substituída por amorfos sílico-ferruginosos; a serpentina da rocha aparece fortemente colorida de amarelo.

A laterita amarela (LA) é um material saprolítico amarelado, de textura mais fina que o SG, menos denso (de 0,6 a 1,2), mas ainda conservando a estrutura da rocha. Ocorre em faixas descontínuas de até $2 \mathrm{~m}$ de espessura. A serpentina ainda está presente neste horizonte mas o mineral predominante é a goethita.

A laterita vermelha (LV) representa o último horizonte do perfil com espessura de 1 a $4 \mathrm{~m}$. Nela, o volume do material original não é mais conservado, havendo compactação e possivel remanejamento. O material é pulverulento, comportando concreçoes ferruginosas oolíticas e pisolíticas, eventualmente soldadas em crosta. Nesta fácies, dominam a goethita e a hematita.

Nos topos dos morrotes, não há perfis tão desenvolvidos: a rocha dura é apenas recoberta por cerca de meio metro de laterita vermelha. É comum a presença de veios de quartzo e garnierita cortando a rocha, chegando, por vezes, a um verdadeiro silcrete.

E. Evolução mineralógica A Fig. 3 resume a hipótese explicativa a respeito da origem e do destino de cada mineral. Os primeiros minerais a se alterarem, carbonatos e brucita, são dissolvidos sem deixar resíduo. Depois altera-se a olivina, da qual resta um resíduo sílico-ferruginoso que acaba evoluindo em quartzo, goethita e hematita. Pode haver neoformação incipiente e transitória de esmectita. Nesse estágio inicial (RD, SG), o retículo de serpentina é fortemente colorido pela adsorção de hidróxidos de ferro e níquel.

Segue-se a dissolução do piroxênio com neoformação de nontronita que, finalmente, resulta na individualização do $\mathrm{Fe}$ e do Al como goethita e boehmita.

Por último, altera-se a serpentina (na LA) e dela nada mais resta senão o Fe sob a forma de goethita e hematita. Resistem ao intemperismo e são encontrados nos horizontes mais alterados os opacos parcialmente oxidados e os filossilicatos mistos flogopita-vermiculitaclorita, ligeiramente evoluídos (Oliveira e Melfi, 1979)

Nos veios de carbonatos e serpentina, ocorrem neoformações de filossilicatos niquelíferos da família kerolita-pimelita (garnieritas, Brindley e Hang, 1973; e Brindley e Maksimovic, 1974). Esses constituintes são dissolvidos em estágios relativamente precoces da alteração. O quartzo, precipitado um pouco mais tarde, resiste e se conserva nos horizontes mais alterados.

$$
\begin{aligned}
& \begin{array}{llllll}
\text { R. original } & \text { R. Serpentinizada } & \text { RD } & S G & S F & L V
\end{array}
\end{aligned}
$$

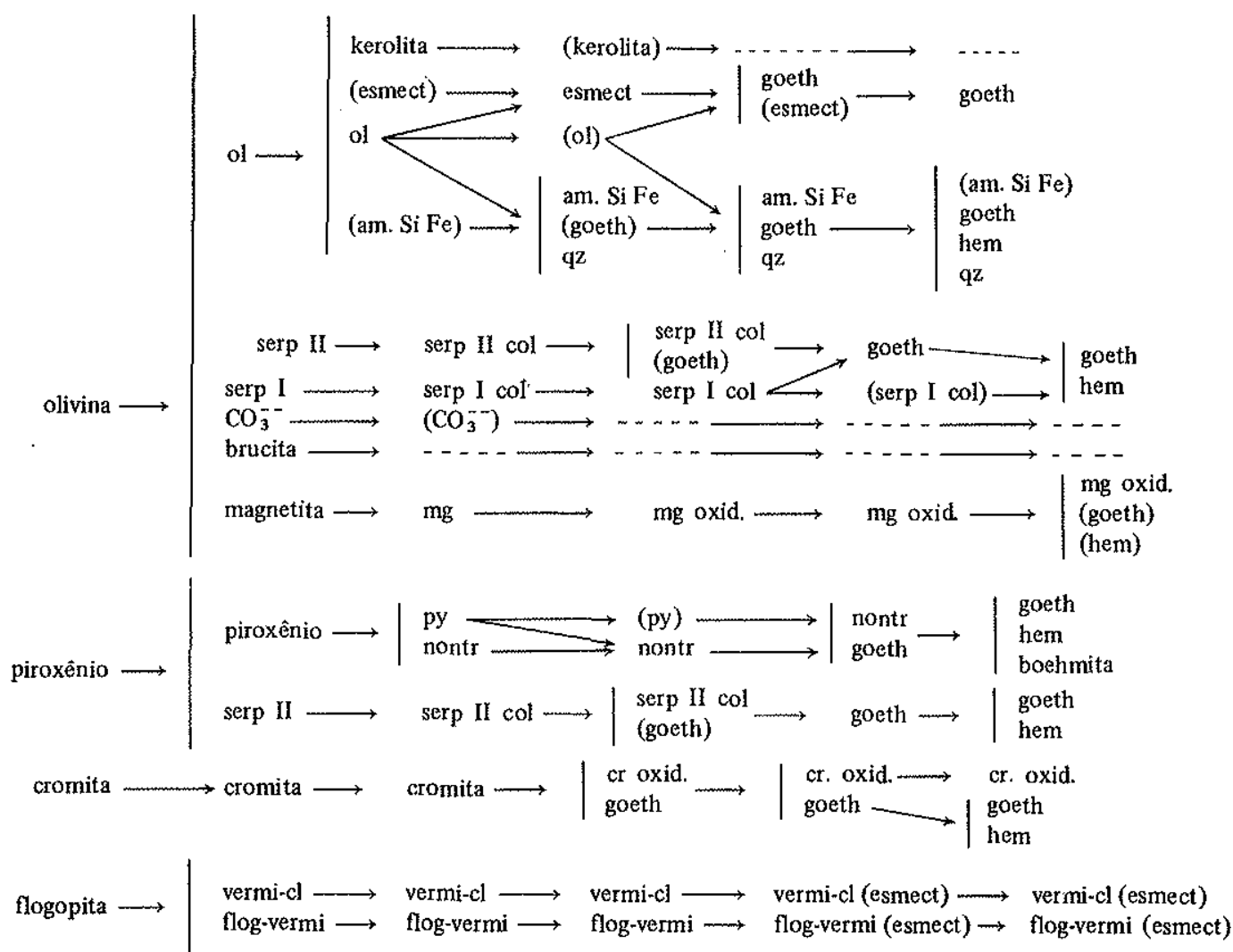




\section{TENDÊNCIAS DA EVOLUÇÃo GEOQUímICA NAS BAIXADAS}

A. Evolução geral dos elementos Os dados apresentados na Tab. 1 indicam a composição química média de cada fácies de alteração. Evidenciam-se imediatamente três grupos de óxidos:

- Os que se concentram nas fácies menos alteradas $\left(\mathrm{SiO}_{2}\right.$ e $\mathrm{MgO}$ ).

- Os que se concentram nas fácies mais alteradas $\left(\mathrm{Fe}_{2} \mathrm{O}_{3}, \mathrm{Al}_{2} \mathrm{O}_{3}, \mathrm{Cr}_{2} \mathrm{O}_{3}, \mathrm{MnO}_{2}, \mathrm{CuO}\right.$ e $\left.\mathrm{CoO}\right)$.

- Os de comportamento irregular $\left(\mathrm{H}_{2} \mathrm{O}\right.$ e $\left.\mathrm{NiO}\right)$.

Tabela 1 - Composiçãu química média ( $\%$ em peso) das fácies de alteração sobre dunito

\begin{tabular}{l|l|l|c|c|c|c}
\hline & $\mathrm{R}$ & $\mathrm{RD}$ & $\mathrm{SG}$ & LA & LV & Canga \\
\hline $\mathrm{SiO}_{2}$ & 39,4 & 41,0 & 40,8 & 30,9 & 10,1 & 10,3 \\
$\mathrm{MgO}$ & 40,2 & 33,4 & 28,3 & 16,4 & 1,6 & 0,8 \\
$\mathrm{Fe}_{2} \mathrm{O}_{3} *$ & 9,0 & 10,4 & 15,5 & 34,6 & 70,8 & 64,9 \\
$\mathrm{Al}_{2} \mathrm{O}_{3}$ & 0,4 & 0,5 & 0,7 & 1,9 & 3,5 & 3,2 \\
$\mathrm{Cr}_{2} \mathrm{O}_{3}$ & 0,39 & 0,44 & 0,64 & 2,21 & 6,20 & 5,26 \\
$\mathrm{NiO}$ & 0,29 & $0,33 * *$ & 0,91 & 1,72 & 1,19 & 1,15 \\
$\mathrm{MnO}$ & 0,22 & 0,20 & 0,28 & 0,44 & 1,01 & 2,38 \\
$\mathrm{CuO}$ & 0,003 & 0,004 & 0,005 & 0,009 & 0,011 & 0,006 \\
$\mathrm{CoO}$ & 0,020 & 0,024 & 0,028 & 0,063 & 0,145 & 0,382 \\
$\mathrm{H}_{2} \mathrm{O}+$ & 9,0 & 12,8 & 12,2 & 11,2 & 5,2 & 12,8 \\
n. amos. & 2 & 39 & 19 & 11 & 18 & 1 \\
densid. & 2,75 & 2,20 & 1,55 & 1,05 & - & 1,90 \\
\hline
\end{tabular}

* Fe total computado como $\mathrm{Fe}^{3+}$

** Excluidos os veios de garnierita

A fim de detalhar esta noção de semelhança e diferença no comportamento químico dos elementos durante o processo de alteração, foram calculados os coeficientes de correlação Pearson entre cada par de oito dos elementos dosados, e o resultado é apresentado na Tab. 2. Fica claro que a classificação dos elementos nos três grupos mencionados é confirmada. Os elementos do primeiro grupo mostram entre si coeficientes de correlação positivos e correlação negativa com os elementos do segundo grupo; estes últimos apresentam entre si correlação positiva. $\mathrm{O}$ Ni não apresenta correlação significativa com nenhum outro elemento.

Tabela 2 - Coeficientes de correlação Pearson entre os teores de $\mathrm{Mg}, \mathrm{Fe}, \mathrm{Cr}, \mathrm{Co}, \mathrm{Cu}, \mathrm{Si}, \mathrm{Al}$ e Ni (284 amostras)

\begin{tabular}{l|c|c|c|c|c|c|c}
\hline$* \mathrm{Fe}$ & $-0,85$ & & & & & & \\
$* \mathrm{Cr}$ & $-0,67$ & $+0,78$ & & & & & \\
$* \mathrm{Co}$ & $-0,74$ & $+0,87$ & $+0,68$ & & & & \\
$* \mathrm{Cu}$ & $-0,57$ & $+0,53$ & $+0,40$ & $+0,49$ & & & \\
$* \mathrm{Si}$ & $+0,59$ & $-0,89$ & $-0,73$ & $-0,78$ & $-0,53$ & & \\
$* \mathrm{Al}$ & $-0,53$ & $+0,49$ & $+0,21$ & $+0,45$ & $+0,55$ & $-0,48$ & \\
$* \mathrm{Ni}$ & 0,00 & $+0,06$ & $-0,09$ & $+0,03$ & $+0,19$ & $+0,04$ & $+0,12$ \\
\hline & $\mathrm{Mg}$ & $\mathrm{Fe}$ & $\mathrm{Cr}$ & $\mathrm{Co}$ & $\mathrm{Cu}$ & $\mathrm{Si}$ & $\mathrm{Al}$ \\
\hline
\end{tabular}

* Rejeição da hipótese Ho (não existe correlação linear entre os pares) para uma probabilidade de 0,001

** Aceitação da hipótese Ho para probabilidade de 0,001

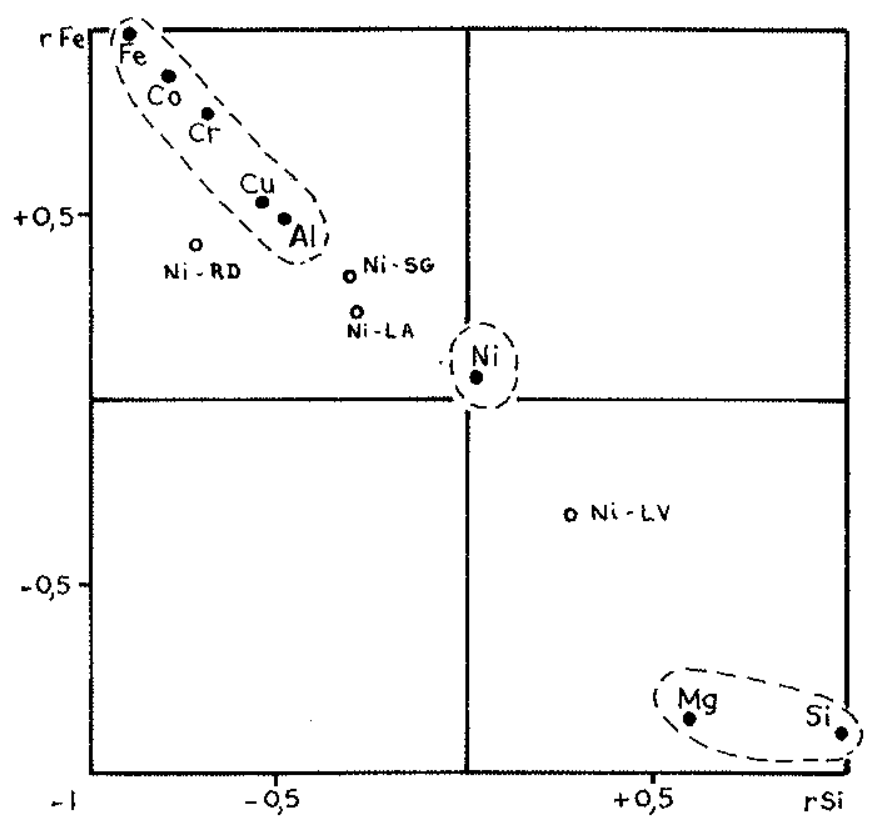

Figura 4 - Representação gráfica dos coeficientes de correlação do $\mathrm{Mg}, \mathrm{Fe}, \mathrm{Cr}, \mathrm{Co}, \mathrm{Cu}, \mathrm{Si}, \mathrm{Al}$ e $\mathrm{Ni}$ em função dos coeficientes de correlação do $\mathrm{Fe}$ e do $\mathrm{Si}$. (Para o Ni, foi também plotado o coeficiente para cada fácies de alteração)

Esses três grupos são bem evidenciados na Fig. 4, em que foram plotados sobre dois eixos ortogonais os coeficientes de correlação de cada elemento com o Fe e o Si. Estes foram escolhidos como referência por apresentar entre si o coeficiente de correlação negativo maior em valor absoluto, isto é, o comportamento mais discrepante. Os coeficientes de correlação do Ni calculados para cada fácies de alteração evidenciam um comportamento solúvel deste elemento na $\mathrm{LV}$ e residual nos demais horizontes.

Os dados acima vêm corroborar as conclusões sobre a evolução mineralógica. A perda dos elementos solúveis traz, por si só, como conseqựencia, a relativa concentração dos elementos menos móveis. O Fe, que com o Si e $\mathrm{Mg}$ perfaz $90 \%$ da rocha, apresenta um comportamento simétrico ao desses dois, isto é, seu teor aumenta à medida que os teores deles diminuem.

$\mathrm{OCr}$, originalmente na cromita, sofre dissolução incipiente e segue o mesmo comportamento que o $\mathrm{Fe}$. $\mathrm{O}$ $\mathrm{Al}$, presente na vermiculita e secundariamente na cromita, permanece, em sua maior parte, retido nesses minerais residuais.

O Mn e o Co não foram encontrados individualizados em minerais. Apresentam comportamento semelhante sendo que o enriquecimento é mais pronunciado para o Co que para o Mn. Encontram-se especialmente concentrados nas crostas ferruginosas. $\mathrm{O} C \mathrm{Cu}$ sofre enriquecimento não muito acentuado no decorrer da meteorização. Sua vinculação mineralógica é desconhecida.

A água, presente originalmente na serpentina, brucita e vermiculita, é também encontrada em quase todos os minerais secundários. Apenas os horizontes de LV são relativamente desidratados como conseqüência da passagem goethita-hematita. No processo de concrecionamento e formação de crosta há novamente hidratação. 
A evolução do Ni é a mais complexa. É liberado do retículo da olivina quando de sua dissolução num meio em que as condições de pH são favoráveis a sua precipitação (junto com o Fe). Daí os teores mais elevados nos níveis de RD e de SG. Pode localmente concentrar-se nas vênulas, associando-se ao $\mathrm{Si}$ e $\mathrm{Mg}$ (pimelita), mas isso representa apenas uma pequena fração do Ni total, pois sua maior parte está associada ao $\mathrm{Fe}$, colorindo a serpentina herdada, ou aos amorfos sílico-ferruginosos. Quando a serpentina se dissolve, o $\mathrm{Ni}$, tal comc o $\mathrm{Fe}$, acumula-se chegando a teores elevados na LA. Com exceção dos raros veios de pimelita, o Ni não forma seus próprios minerais. Sua distribuição e a natureza de sua associação com o Fe serão discutidas adiante. $\mathrm{Na} \mathrm{LV} \mathrm{o}$ declínio dos teores de Ni acompanha a passagem goethita-hematita.

No caso dos piroxenitos e peridotitos, a evolução química é essencialmente a mesma. $\mathrm{O} \mathrm{Ca}$, presente no diopsídio, comporta-se de maneira semelhante ao $\mathrm{Mg}$, sendo evacuado à medida de sua liberação.

B. Balanço global da alteração (dunitos) A conser. vação da estrutura original da rocha durante a alteração até o nível de LA permite calcular a quantidade de cada elemento por unidade de volume e compará-la com a quantidade inicialmente presente no mesmo volume de rocha fresca (balanço isovolumétrico, Millot e Bonifas, 1955). Assim, para cada amostra, os dados das análises químicas ponderais foram multiplicados pelos de densidade aparente, sendo os resultados expressos em $\mathrm{g} / 100 \mathrm{~cm}^{3}$.

A Tab. 3 mostra o balanço global da alteração meteórica para os dunitos de Santa Fé, calculado para cada estágio do processo. As perdas são contínuas e fortes para o $\mathrm{Mg}$ e, em menor grau, para o $\mathrm{Si}$; esses dois elementos são evacuados em solução, depois de liberados dos minerais hipógenos (olivina e serpentina). A Fig. 5 permite a comparação das velocidades respectivas de lixiviação desses elementos solúveis. A rápida perda inicial de $\mathrm{MgO}$ (4\% do $\mathrm{MgO}$ total) corresponde à dissolução da brucita e dos carbonatos. Em seguida, a evacuação preferencial do $\mathrm{MgO}$ demonstra que a hidrólise da olivina deixa um resíduo sílico-(ferruginoso). No SG e na LA, a alteração da serpentina é praticamente uma dissolução congruente.
$\mathrm{O} F e$, o $\mathrm{Al}$ e o $\mathrm{Cr}$ permanecem em quantidades mais ou menos constantes até o SG, mas são enriquecidos em valor absoluto nas LA mais evoluídas, provavelmente por consequêencia de uma iluviação de finas partículas, a partir da LV. O Ni revela enriquecimen tos absolutos em todos os níveis de alteração, a não ser na RD, onde ele é apenas conservado.

Na LV, a estrutura da rocha é destruída, o que impossibilita o cálculo isovolume. Uma avaliação grosseira do balanço foi tentada usando a média dos resultados obtidos considerando, sucessivamente, o Fe e o Al constantes na passagem LA-LV. A quase totalidade do Si e sobretudo do Mg iniciais desaparecem na LV. Esse nível tem um pouco menos de Ni que a rocha fresca. Enfim, é provável que a $\mathrm{LV}$ tenha um excesso de $\mathrm{Cr}$ em relação à LA.

A Tab. 3 mostra a importância da proporção de material evacuado $\left(\mathrm{SiO}_{2}, \mathrm{MgO}\right)$ : no final da alteração (LV), $86 \%$ da rocha inicial foram dissolvidos. A proporção de material importado nunca é muito grande.

Portanto a evolução dos perfis de alteração das rochas de Santa Fé pode ser caracterizada como uma laterização. Esses perfis são todos localizados na baixada (superfície Velhas e evolução recente). Por outro lado, a baixada mostra um excedente de $\mathrm{Fe}$, Al e $\mathrm{Cr}$ nos horizontes superiores, e de $\mathrm{Ni}$ em quase todos os níveis, sem fonte atual para essas acumulações absolutas.

\section{Distribuição dos elementos nos minerais (duni-} tos) As análises químicas sobre amostra total e o cálculo do balanço geoquímico forneceram informaçðes a respeito da evolução geral dos elementos químicos, no decorrer da alteração. É interessante relacionar essa evolução às filiações mineralógicas sucessivas a fim de esclarecer o destino e a repartição dos elementos nas diferentes fases mineralógicas, em cada etapa do processo.

$\mathrm{Na}$ rocha fresca, essa abordagem pode ser direta com a análise dos minerais puros separados. Nos horizontes de alteração, os minerais secundários ocorrem, em geral, misturados e são de granulação muito fina, impossibilitando a separação. Neste caso, abordagens indiretas, como análise de fraçð̃es granulométricas e ataques químicos parciais, são muito úteis.

Tabela 3 - Balanço dos ganhos e das perdas médias em cada horizonte ${ }^{1}$

\begin{tabular}{l|l|l|l|l|l|l|l|l|l}
\hline & $\mathrm{H}_{2} \mathrm{O}+$ & $\mathrm{SiO}_{2}$ & $\mathrm{MgO}$ & $\mathrm{Fe}_{2} \mathrm{O}_{3}$ & $\mathrm{Al}_{2} \mathrm{O}_{3}$ & $\mathrm{Cr}_{2} \mathrm{O}_{3}$ & $\mathrm{NiO}$ & Export. $^{2}$ & Import. $^{3}$ \\
\hline $\mathrm{LV}$ & -89 & -95 & -99 & +48 & +60 & +200 & -24 & $86 \%$ & $28 \%$ \\
$\mathrm{LA}$ & -53 & -70 & -85 & +47 & +80 & +130 & +126 & $68 \%$ & $15 \%$ \\
$\mathrm{SG}$ & $-23,8$ & $-41,6$ & $-60,3$ & -3 & $-5,5$ & $-7,3$ & +76 & $41 \%$ & $0,39 \%$ \\
$\mathrm{RD}$ & +13 & $-16,7$ & $-33,5$ & $-7,5$ & $-4,3$ & $-9,5$ & $-7,4$ & $20 \%$ & - \\
$\mathrm{R}^{4}$ & 24,83 & 108,32 & 110,44 & 24,72 & 1,15 & 1,07 & 0,80 & - & - \\
\hline
\end{tabular}

1 Ganhos (+) e perdas (-) em porcentagem da quantidade inicial de cada óxido

2 Proporcão do material inicial

3 Proporção do material do horizonte

4 Quantidades iniciais em $\mathrm{g} / 100 \mathrm{~cm}^{3}$ 


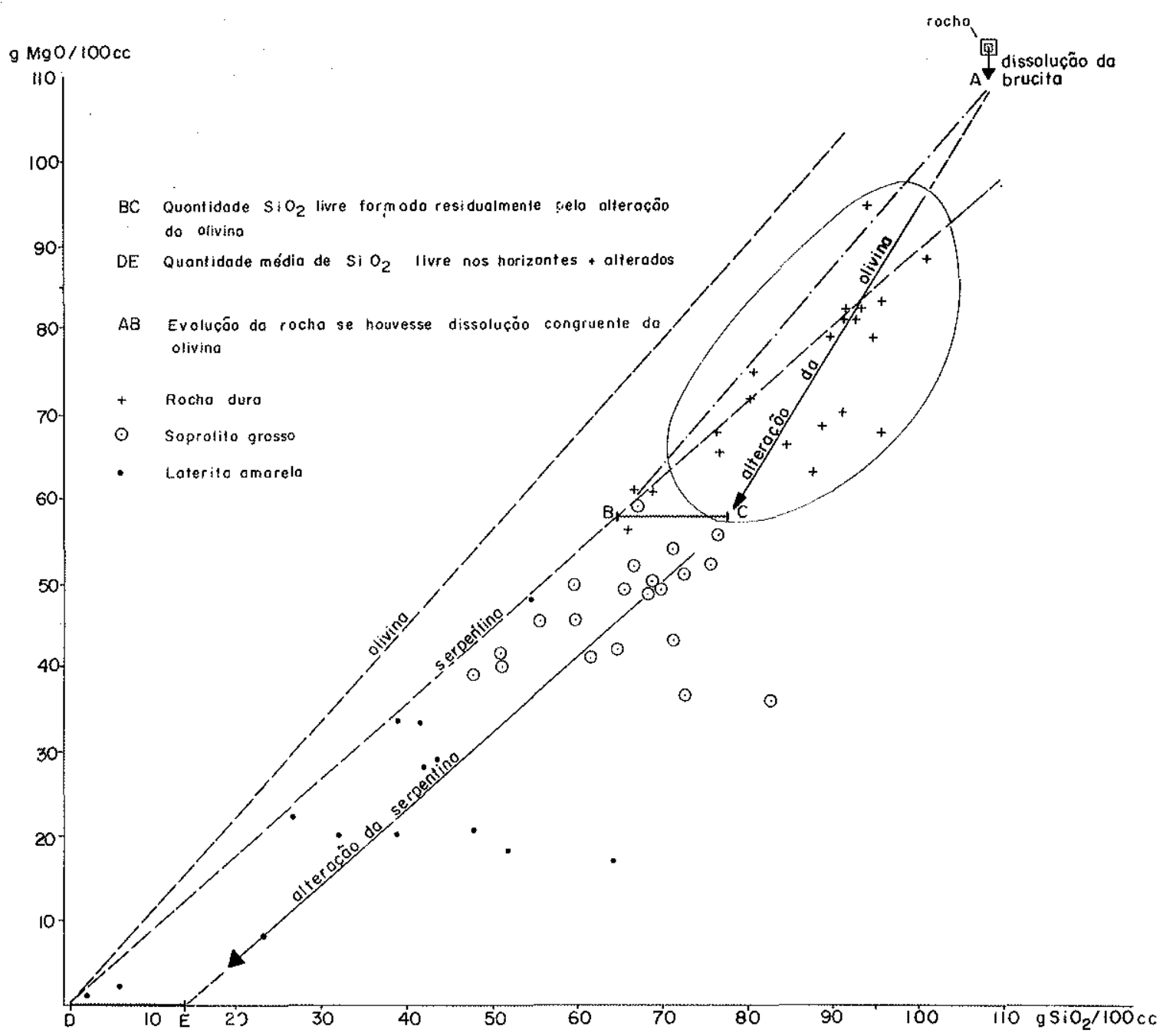

Figura 5 - Evolução dos elementos solúveis na alteração

\section{Composição dos minerais hipógenos na rocha fresca}

A Tab. 4 fornece a composição e a fórmula estrutural dos minerais hipógenos dos dunitos (olivina, serpen- tina e vermiculita) e do piroxênio (Souza, 1978; e Olivei$\mathrm{ra}, 1980$ ). A transformação hipógena olivina-serpentina parece ter acontecido com aumento de volume e sem perda de Ni.

Tabela 4 - Composição química (\% em peso) e fórmula estrutural dos minerais hipógenos

\begin{tabular}{l|l|l|l|l|c|c|c|c|c|c|c|c|c|c} 
& $\mathrm{H}_{2} \mathrm{O}+$ & $\mathrm{SiO}_{2}$ & $\mathrm{MgO}$ & $\mathrm{FeO}$ & $\mathrm{Fe}_{2} \mathrm{O}_{3}$ & $\mathrm{Al}_{2} \mathrm{O}_{3}$ & $\mathrm{Cr}_{2} \mathrm{O}_{3}$ & $\mathrm{NiO}$ & $\mathrm{CoO}$ & $\mathrm{CuO}$ & $\mathrm{MnO}_{2}$ & $\mathrm{CaO}$ & $\mathrm{TiO}_{2}$ & $\mathrm{Total}$ \\
\hline Olivina & 0 & 40,60 & 45,12 & 10,71 & - & 0,24 & 0,03 & 0,35 & - & - & 0,27 & 0,32 & 0,01 & 97,65 \\
Piroxênio & 0 & 51,69 & 15,45 & 5,24 & - & 1,85 & 0,05 & 0,06 & - & - & 0,03 & 23,12 & 1,47 & 98,96 \\
Serpentina & 14,0 & 40,8 & 36,5 & 6,40 & - & 0,20 & 0,06 & 0,27 & 0,01 & 0,010 & 0,07 & 0,08 & - & 98,40 \\
Vermiculita & 16,0 & 35,70 & 30,85 & - & 7,80 & 10,40 & 0,04 & 0,08 & 0,01 & 0,025 & 0,04 & 1,00 & - & 101,95 \\
(em veios) & & & & & & & & & & & & \\
\hline
\end{tabular}

Olivina $\quad\left(\mathrm{Mg}_{1,69} \mathrm{Fe}_{0,23}^{\mathrm{Il}} \mathrm{Al}_{0,01} \mathrm{Ni}_{0,01} \mathrm{Mn}_{0,01} \mathrm{Ca}_{0.01}\right) \mathrm{Si}_{1,01} \mathrm{O}_{4}$

Piroxênio $\quad\left(\mathrm{Mg}_{0,43} \mathrm{Fe}_{0,08}^{\mathrm{ll}} \mathrm{Ca}_{0,46} \mathrm{Ti}_{0,02}\right)\left(\mathrm{Si}_{0,96} \mathrm{Al}_{0,04}\right) \mathrm{O}_{3}$

Vermiculita $\left(\mathrm{Mg}_{0,84} \mathrm{Ca}_{0,16}\right)\left(\mathrm{Mg}_{6,00}\right)\left[\left(\mathrm{Si}_{5,31} \mathrm{Al}_{3,82} \mathrm{Fe}_{0,87}^{[\mathrm{ll}}\right) \mathrm{O}_{99,6} \mathrm{l}(\mathrm{OH})_{4} \cdot 6 \mathrm{H}_{2} \mathrm{O}\right.$

Serpentina $\quad\left(\mathrm{Mg}_{2,60} \mathrm{Fe}_{0,26}^{\mathrm{II}} \mathrm{Ni}_{0,01} \mathrm{Al}_{0,01}\right) \mathrm{Si}_{2} \mathrm{O}_{5}(\mathrm{OH})_{4}$ 


\section{Avaliação da composição dos produtos secundários}

a) Garnierita A análise de várias amostras de composição mineralógica conhecida permitiu avaliar a fórmula estrutural da pimelita, silicato niquelífero exclusivo das garnieritas: $\left(\mathrm{Mg}_{1,86} \mathrm{Ni}_{1,14}\right)\left(\mathrm{Si}_{3,83} \mathrm{Al}_{0,06} \mathrm{Fe}_{0,11}^{\mathrm{III}}\right)$ $\mathrm{O}_{10}(\mathrm{OH})_{2} \mathrm{H}_{2} \mathrm{O}$.

b) Ataques químicos parciais A análise química de dunitos frescos ou alterados, por ataque perclórico, deixa como único resíduo insolúvel o quartzo, que pode assim ser contabilizado separadamente da sílica dos silicatos e da sílica amorfa (conjunto "sílica solúvel").

Também foi dosada, segundo o método Segalen (1968), a proporção de Fe e Ni amorfos ou mal cristalizados em cada horizonte (Tab. 5).

Tabela 5 - Proporção dos óxidos amorfos e mal cristalizados em relação a sua quantidade total na amostra (em \%)

\begin{tabular}{l|c|c|c}
\hline & $\mathrm{Fe}_{2} \mathrm{O}_{3}$ & $\mathrm{NiO}$ & $\mathrm{MgO}$ \\
\hline $\mathrm{LV} / \mathrm{LA}$ & 60 & 77 & 0 \\
$\mathrm{LA}$ & 68 & 78 & 0 \\
$\mathrm{SG}$ & 92 & 100 & 0 \\
\hline
\end{tabular}

A diminuição da proporção de material amorfo em direção ao topo dos perfis confirma que a olivina, e de pois a serpentina, é hidrolisada deixando um resíduo (sílico)-ferruginoso-niquelífero amorfo, que passa gradativamente a goethita. Este resíduo amorfo não retém o $\mathrm{Mg}$ liberado dos silicatos primários.

c) Análise das frações granulométricas Três frações granulométricas (A: $\varnothing>0,25 \mathrm{~mm} ; \quad B: 0,25 \mathrm{~mm}>\emptyset$ $>0,062 \mathrm{~mm}$; e $\mathrm{C}: \emptyset<0,062 \mathrm{~mm}$ ) dos quatro horizontes de alteração de um perfil foram analisadas (Tab. 6).
Na RD, a fração grosseira predomina. Todas as fraçôes têm composição semelhante e próxima à da $R$ (desagregação mecânica). Ocorre apenas uma perda de $\mathrm{Mg}$ levemente maior na fração fina, onde são concentrados os produtos amorfos sílico-ferruginosos da alteração da olivina.

No SG, em que predomina a fração fina, as três frações são nitidamente diferentes. A fração grosseira é basicamente constituida de serpentina mas enriquecida em $\mathrm{Fe}$ e sobretudo em Ni; é a "serpentina colorida" descrita na evolução mineralógica. A fração média concentra os grãos de cromita. O teor de $\mathrm{Cr}$ na fração fina mostra que começou a alteração deste espinélio. A fração fina $(17,8 \% \mathrm{MgO})$ contém aproximadamente $50 \%$ de serpentina microdividida e $50 \%$ do material sílico-ferruginoso-niquelifero amorfo (antigos núcleos de olivina, agora totalmente alterados).

Na LA, as frações mais grosseiras são pouco significativas em quantidade e compõem-se de uma proporção considerável de cromita. Um terço do $\mathrm{Cr}$ da amostra total pertence à fração fina, o que indica uma proporção semelhante de cromita alterada (com perda de $\mathrm{Mg}$, Trescases, 1975).

$\mathrm{Na} L V$, as três frações voltam a ser quimicamente parecidas, todas muito ferruginosas, aluminosas e cromíferas (alteração de $50 \%$ das cromitas). A dessilicificação da fração fina em relação a mesma fração na LA é mais intensa que a perda de $\mathrm{Mg}$ concomitante (dessilicificação dos géis sílico-ferruginosos). $\mathrm{O}$ aumento da fração grosseira traduz o início de concrecionamento.

\section{Cálculo da repartição dos elementos nos minerais em cada horizonte}

a) Distribuiçâo Com base na composição média e na densidade de cada horizonte (Tab. 1), os elementos podem ser distribuídos pelas diferentes fases mineralógicas presentes a cada estágio de alteração, utilizando os resultados do estudo das filiações mineralógicas (Fig. 3), do balanço global da alteração (Tab. 3), dos ataques químicos parciais (Tab. 5) e da análise das frações gra-

Tabela 6 - Análise química das frações granulométricas ( $\%$ em peso)

\begin{tabular}{|c|c|c|c|c|c|c|c|c|c|c|c|c|c|c|}
\hline & & $\mathrm{H}_{2} \mathrm{O}+$ & $\mathrm{Qz}$ & $\mathrm{SiO}_{2}$ sol. & $\mathrm{MgO}$ & $\mathrm{Fe}_{2} \mathrm{O}_{3}$ & $\mathrm{Al}_{2} \mathrm{O}_{3}$ & $\mathrm{Cr}_{2} \mathrm{O}_{3}$ & $\mathrm{NiO}$ & $\mathrm{CoO}$ & $\mathrm{CuO}$ & $\mathrm{MnO}_{2}$ & $\mathrm{CaO}$ & Total \\
\hline $\mathrm{LV}$ & $\begin{array}{l}127 \mathrm{~A}(10)^{*} \\
127 \mathrm{~B}(44) \\
127 \mathrm{C}(46)\end{array}$ & $\begin{array}{l}4,3 \\
2,1 \\
3,1\end{array}$ & $\begin{array}{l}7,3 \\
8,4 \\
8,7\end{array}$ & $\begin{array}{l}4,3 \\
0,4 \\
2,3\end{array}$ & $\begin{array}{l}1,0 \\
1,6 \\
1,7\end{array}$ & $\begin{array}{l}63,0 \\
75,3 \\
74,5\end{array}$ & $\begin{array}{l}5,8 \\
3,6 \\
3,3\end{array}$ & $\begin{array}{l}7,02 \\
6,09 \\
6,31\end{array}$ & $\begin{array}{l}0,80 \\
0,79 \\
0,72\end{array}$ & $\begin{array}{l}0,239 \\
0,120 \\
0,068\end{array}$ & $\begin{array}{l}0,012 \\
0,008 \\
0,036\end{array}$ & $\begin{array}{l}1,19 \\
0,63 \\
0,35\end{array}$ & $\begin{array}{c}4,45 \\
- \\
-\end{array}$ & $\begin{array}{r}99,4 \\
99,0 \\
101,1\end{array}$ \\
\hline LA & $\begin{array}{l}124 \mathrm{~A}(3) \\
124 \mathrm{~B} \mathrm{(9)} \\
124 \mathrm{C}(88)\end{array}$ & $\begin{array}{r}10,5 \\
1,6 \\
11,1\end{array}$ & $\frac{14,8}{5,3}$ & $\begin{array}{c}26,6 \\
5,44- \\
12,5\end{array}$ & $\begin{array}{r}20,8 \\
6,0 \\
6,6\end{array}$ & $\begin{array}{l}23,3 \\
51,9 \\
56,5\end{array}$ & $\begin{array}{l}0,4 \\
2,0 \\
0,8\end{array}$ & $\begin{array}{r}1,32 \\
23,54 \\
0,92\end{array}$ & $\begin{array}{l}2,39 \\
1,25 \\
3,37\end{array}$ & $\begin{array}{l}0,029 \\
0,076 \\
0,076\end{array}$ & $\begin{array}{l}0,006 \\
0,004 \\
0,086\end{array}$ & $\begin{array}{l}0,27 \\
0,59 \\
0,52\end{array}$ & $\begin{array}{c}0,13 \\
0,04 \\
-\end{array}$ & $\begin{array}{r}100,5 \\
102,4 \\
97,8\end{array}$ \\
\hline SG & $\begin{array}{l}123 \mathrm{~A}(10) \\
123 \mathrm{~B}(16) \\
123 \mathrm{C}(74)\end{array}$ & $\begin{array}{r}12,3 \\
8,2 \\
13,6\end{array}$ & $\begin{array}{l}3,0 \\
3,3 \\
0,9\end{array}$ & $\begin{array}{l}34,0 \\
23,2 \\
22,9\end{array}$ & $\begin{array}{l}24,6 \\
20,0 \\
17,8\end{array}$ & $\begin{array}{l}22,9 \\
34,8 \\
43,0\end{array}$ & $\begin{array}{l}0,3 \\
1,1 \\
0,3\end{array}$ & $\begin{array}{l}0,31 \\
9,48 \\
0,46\end{array}$ & $\begin{array}{l}1,78 \\
1,44 \\
2,51\end{array}$ & $\begin{array}{l}0,038 \\
0,041 \\
0,081\end{array}$ & $\begin{array}{l}0,004 \\
0,011 \\
0,053\end{array}$ & $\begin{array}{l}0,29 \\
0,34 \\
0,60\end{array}$ & $\begin{array}{l}0,07 \\
0,07 \\
0,56\end{array}$ & $\begin{array}{l}100,1 \\
101,9 \\
101,9\end{array}$ \\
\hline RD & $\begin{array}{l}122 \mathrm{~A}(70) \\
122 \mathrm{~B}(10) \\
122 \mathrm{C}(20)\end{array}$ & $\begin{array}{l}12,0 \\
11,8 \\
13,1\end{array}$ & $\begin{array}{l}1,2 \\
1,4 \\
1,5\end{array}$ & $\begin{array}{l}36,8 \\
39,0 \\
38,3\end{array}$ & $\begin{array}{l}34,5 \\
31,6 \\
30,7\end{array}$ & $\begin{array}{l}16,5 \\
15,0 \\
15,8\end{array}$ & $\begin{array}{l}0,2 \\
1,2 \\
0,8\end{array}$ & $\begin{array}{l}0,58 \\
1,62 \\
0,52\end{array}$ & $\begin{array}{l}0,46 \\
0,60 \\
0,69\end{array}$ & $\begin{array}{l}0,024 \\
0,029 \\
0,058\end{array}$ & $\begin{array}{l}0,003 \\
0,003 \\
0,025\end{array}$ & $\begin{array}{l}0,21 \\
0,22 \\
0,42\end{array}$ & $\begin{array}{l}0,10 \\
0,35 \\
0,45\end{array}$ & $\begin{array}{l}102,6 \\
102,8 \\
102,4\end{array}$ \\
\hline
\end{tabular}

* Os números entre parênteses correspondem à porcentagem da fração granulométrica considerada

- Não determinado 
nulométricas (Tab. 6), segundo o método proposto por Trescases, 1975. Os resultados, sempre para $100 \mathrm{~cm}^{3} \mathrm{de}$ amostra (avaliação isoFe-iso Al, para a LV), constam das tabelas seguintes.

Rocha fresca: Tab. 7 (composição estimada para os carbonatos e cromita).

Rocha dura: Tab. 8 (a garnierita não foi considerada por ser muito rara, principalmente na baixada).
Saprolito grosso: Tab. 9. O material não pertencente aos minerais primários é distribuído entre o gel $\mathrm{Si}-\mathrm{Fe}-$ ex-olivina - e os produtos niquelífero - ferruginosos que colorem a serpentina, conforme as análises das fraçðes granulométricas (esses produtos $\mathrm{Fe}-\mathrm{Ni}$ são absorvidos nos defeitos da malha de serpentina nas clivagens, no canal central, etc. (Trescases, 1975 e 1979).

Laterita amarela: Tab. 10. A quase totalidade da serpentina constante da fração fina é muito desagregada e não deve reter grande quantidade de produtos $\mathrm{Fe}-\mathrm{Ni}$.

Tabela 7 - Distribuição dos elementos por minerais na rocha fresca $(D=2,75)$

\begin{tabular}{l|c|c|c|c|c|c|c|c}
\hline $\mathrm{g} / 100 \mathrm{~cm}^{3}$ & $\begin{array}{c}\mathrm{H}_{2} \mathrm{O} \\
+\mathrm{CO}_{2}\end{array}$ & $\mathrm{SiO}_{2}$ & $\mathrm{MgO}$ & $\mathrm{Fe}_{2} \mathrm{O}_{3}(1)$ & $\mathrm{Al}_{2} \mathrm{O}_{3}$ & $\mathrm{Cr}_{2} \mathrm{O}_{3}$ & $\mathrm{NiO}$ & $\begin{array}{c}\text { Total } \\
(2)\end{array}$ \\
\hline Olivina & - & 46,56 & 51,73 & 13,64 & 0,275 & 0,027 & 0,38 & 112,61 \\
Serpentina & 21,01 & 61,27 & 54,81 & 10,67 & 0,302 & 0,08 & 0,41 & 148,55 \\
Carbonato & 3,60 & - & 3,27 & - & - & - & - & 6,87 \\
Vermiculita & 0,22 & 0,50 & 0,41 & 0,11 & 0,137 & $-\overline{-}$ & - & 1,38 \\
Cromita & - & - & 0,22 & 0,30 & 0,44 & 0,96 & - & $\mathbf{1 , 9 2}$ \\
Total & $\mathbf{2 4 , 8 3}$ & $\mathbf{1 0 8 , 3 2}$ & $\mathbf{1 1 0 , 4 4}$ & $\mathbf{2 4 , 7 2}$ & $\mathbf{1 , 1 5}$ & $\mathbf{1 , 0 7}$ & $\mathbf{0 , 8 0}$ & $\mathbf{2 7 1 , 3 3}$ \\
\hline
\end{tabular}

(1) Fe total como $\mathrm{Fe}_{2} \mathrm{O}_{3}$

(2) Peso de cada minerăl em $\mathrm{g} / 100 \mathrm{~cm}^{3}$ de rocha

Tabela 8 - Distribuição dos elementos por minerais na rocha dura $(D=2,2)$

\begin{tabular}{l|c|c|c|c|c|c|c|c}
\hline $\mathrm{g} / 100 \mathrm{~cm}^{3}$ & $\mathrm{H}_{2} \mathrm{O}$ & $\mathrm{SiO}_{2}$ & $\mathrm{MgO}$ & $\mathrm{Fe}_{2} \mathrm{O}_{3}$ & $\mathrm{Al}_{2} \mathrm{O}_{3}$ & $\mathrm{Cr}_{2} \mathrm{O}_{3}$ & $\mathrm{NiO}$ & $\begin{array}{c}\text { Total } \\
(2)\end{array}$ \\
\hline Olivina & - & 16,23 & 18,04 & 4,75 & 0,10 & 0,01 & 0,14 & 39,27 \\
Serpentina & 21,04 & 61,27 & 54,81 & 10,67 & 0,302 & 0,08 & 0,41 & 148,55 \\
Vermiculita & 0,22 & 0,50 & 0,41 & 0,11 & 0,137 & - & - & 1,38 \\
Cromita & - & - & 0,22 & 0,30 & 0,44 & 0,96 & - & 1,92 \\
Gel Si-Fe & 6,93 & 10,2 & - & 8,90 & 0,17 & 0,02 & 0,25 & 26,47 \\
Quartzo & $-\overline{28,16}$ & $\mathbf{9 0 , 2}$ & $\mathbf{7 3 , 4 8}$ & $\mathbf{2 4 , 7 2}$ & $\mathbf{1 , 1 5}$ & $\mathbf{1 , 0 7}$ & $\mathbf{0 , 8 0}$ & $\mathbf{2 1 9 , 5 9}$ \\
Total & & & & &
\end{tabular}

(1) Fe total como $\mathrm{Fe}_{2} \mathrm{O}_{3}$

(2) Peso de cada mineral em $\mathrm{g} / 100 \mathrm{~cm}^{3}$ de amostra

Tabela 9 - Distribuição dos elementos por mineral no saprolito grosso $(D=1,55)$

\begin{tabular}{l|c|c|c|c|c|c|c|c}
\hline $\mathrm{g} / 100 \mathrm{~cm}^{3}$ & $\mathrm{H}_{2} \mathrm{O}$ & $\mathrm{SiO}_{2}$ & $\mathrm{MgO}$ & $\begin{array}{c}\mathrm{Fe}_{2} \mathrm{O}_{3} \\
(1)\end{array}$ & $\mathrm{Al}_{2} \mathrm{O}_{3}$ & $\mathrm{Cr}_{2} \mathrm{O}_{3}$ & $\mathrm{NiO}$ & $\begin{array}{c}\text { Total } \\
(2)\end{array}$ \\
\hline Vermiculita & 0,22 & 0,50 & 0,41 & 0,11 & 0,137 & - & - & 1,38 \\
Cromita & - & - & 0,20 & 0,27 & 0,40 & 0,86 & - & 1,73 \\
Serpentina & 16,6 & 48,35 & 43,26 & 8,40 & 0,24 & 0,07 & 0,32 & \\
+ & & & & + & + & + & + & 126,14 \\
Residuo Fe-Ni & & 11,5 & - & 8,0 & 0,18 & 0,07 & 0,69 & \\
Gel Si-Fe & 2,1 & 1,5 & - & - & -19 & 0,07 & 0,44 & 22,3 \\
Quartzo & - & 3 & - & - & - & 3 \\
Total & $\mathbf{1 8 , 9 1}$ & $\mathbf{6 3 , 2 4}$ & $\mathbf{4 3 , 8 7}$ & $\mathbf{2 4 , 7 2}$ & $\mathbf{1 , 1 5}$ & $\mathbf{1 , 0 7}$ & $\mathbf{1 , 4 1}$ & $\mathbf{1 5 4 , 5 5}$ \\
\hline
\end{tabular}

(1) $\mathrm{Fe}$ total $\mathrm{Fe}_{2} \mathrm{O}_{3}$

(2) Peso de cada mineral em $\mathrm{g} / 100 \mathrm{~cm}^{3}$ de amostra 
Tabela 10 - Distribuição dos elementos por minerais na laterita amarela $(\mathrm{D}=1,05)$

\begin{tabular}{|c|c|c|c|c|c|c|c|c|}
\hline $\mathrm{g} / 100 \mathrm{~cm}^{3}$ & $\mathrm{H}_{2} \mathrm{O}$ & $\mathrm{SiO}_{2}$ & $\mathrm{MgO}$ & $\begin{array}{c}\mathrm{Fe}_{2} \mathrm{O}_{3} \\
\text { (1) }\end{array}$ & $\mathrm{Al}_{2} \mathrm{O}_{3}$ & $\mathrm{CR}_{2} \mathrm{O}_{3}$ & $\mathrm{NiO}$ & $\begin{array}{l}\text { Total } \\
\text { (2) }\end{array}$ \\
\hline Vermiculita & 0,22 & 0,50 & 0,41 & 0,11 & 0,137 & - & - & 1,38 \\
\hline Cromita & - & - & 0,15 & 0,21 & 0,29 & 0,64 & - & 1,29 \\
\hline Serpentina & 6,38 & 18,60 & 16,64 & 3,24 & 0,09 & 0,03 & 0,12 & 45,10 \\
\hline Gel Si-Fe & 3,06 & 9,38 & - & 16,39 & 0,74 & 0,83 & 1,13 & 31,53 \\
\hline Goethita & 2,06 & - & - & 16,39 & 0,74 & 0,82 & 0,56 & $20,5^{-}$ \\
\hline Quartzo & - & 4 & - & - & - & - & - & 4 \\
\hline Total & 11,72 & 32,48 & 17,20 & 36,34 & 2,00 & 2,32 & $\mathbf{1 , 8 1}$ & 103,87 \\
\hline
\end{tabular}

(1) Fe total como $\mathrm{Fe}_{2} \mathrm{O}_{3}$

(2) Peso de cada mineral em $\mathrm{g} / 100 \mathrm{~cm}^{3}$ de amostra

Tabela 11 - Distribuição dos elementos por minerais na laterita vermelha

\begin{tabular}{l|c|c|c|c|c|c|c|c}
\hline $\mathrm{g} / 100 \mathrm{~cm}^{3}$ & $\mathrm{H}_{2} \mathrm{O}$ & $\mathrm{SiO}_{2}$ & $\mathrm{MgO}$ & $\begin{array}{c}\mathrm{Fe}_{2} \mathrm{O}_{3} \\
(1)\end{array}$ & $\mathrm{Al}_{2} \mathrm{O}_{3}$ & $\mathrm{Cr}_{2} \mathrm{O}_{3}$ & $\mathrm{NiO}$ & $\begin{array}{c}\text { Total } \\
(2)\end{array}$ \\
\hline Vermiculita & 0,22 & 0,50 & 0,41 & 0,11 & 0,137 & 0,48 & - & 1,38 \\
Cromita & - & - & 0,11 & 0,15 & 0,22 & - & - & 0,96 \\
Serpentina & 0,11 & 0,34 & 0,30 & 0,06 & - & - & - & 0,81 \\
Quartzo & - & 3,5 & - & - & - & - & - & 3,5 \\
Gel Si-Fe & 0,52 & 0,87 & - & 3,78 & 0,17 & 0,19 & 0,26 & 5,79 \\
Goethita & 1,83 & - & - & 14,58 & 0,66 & 1,25 & 0,35 & 18,67 \\
Hematita & - & - & - & 17,82 & 0,61 & 1,27 & - & 19,70 \\
Total & $\mathbf{2 , 6 8}$ & $\mathbf{5 , 2 1}$ & $\mathbf{0 , 8 2}$ & $\mathbf{3 6 , 5 0}$ & $\mathbf{1 , 8 0}$ & $\mathbf{3 , 1 9}$ & $\mathbf{0 , 6 1}$ & $\mathbf{5 0 , 8 1}$ \\
\hline
\end{tabular}

(1) Fe total como $\mathrm{Fe}_{2} \mathrm{O}_{3}$

(2) Peso de cada mineral num volume de amostra resultante da evolução de $100 \mathrm{~m}^{3}$ de rocha fresca; esse volume foi avaliado pela média dos cálculos a ferro e alumínio constantes

Laterita vermelha: Tab. 11. A goethita foi considerada idêntica à da LA, e o gel Si-Fe também, com exceção de uma dessilicificação parcial.

As quantidades absolutas de cada mineral em $100 \mathrm{~cm}^{3}$ de cada fácies de alteração são representadas na Fig. $6 B$, verticalmente distribuídas em função da densidade. É assim evidenciada a evolução mineralógica quantitativa dos dunitos. Esse "perfil" pode ser facilmente relacionado à sucessão vertical dos horizontes no perfil de alteração (Fig. 6A). A Tab. 12 resume as porcentagens ponderais médias de cada mineral a cada eta* pa da alteração.

Tabela 12 - Composição mineralógica média de cada horizonte de alteração $(\% \mathrm{em}$ peso)

\begin{tabular}{l|l|c|c|c|c|c|c|c|c}
\hline & Ol & Se & Ca & Ve & Cr & Gel Si-Fe & Qz & Go & He \\
\hline LV & 0 & 1,6 & 0 & 2,7 & 1,9 & 11,4 & 6,9 & 36,7 & 38,8 \\
LA & 0 & 43,4 & 0 & 1,3 & 1,2 & 30,3 & 3,8 & 19,8 & - \\
SG & 0 & 81,6 & 0 & 0,9 & 1,1 & 14,4 & 2,0 & - & - \\
RD & 17,9 & 67,65 & 0 & 0,63 & 0,87 & 12,95 & - & - & - \\
R & 41,7 & 54,6 & 2,5 & 0,5 & 0,7 & - & - & - & - \\
\hline
\end{tabular}

$\begin{array}{ll}\text { Ol - Olivina } & \mathrm{Cr}-\text { Cromita } \\ \mathrm{Se}-\text { Serpentina } & \mathrm{Q} z-\text { Quartzo } \\ \mathrm{Ca} \text {-Carbonato } & \mathrm{Go}-\text { Goethita } \\ \mathrm{Ve} \text { - Vermiculita } & \mathrm{He}-\text { Hematita }\end{array}$

b) Composição dos produtos de alteração da olivina $e$ da serpentina A composição calculada dos produtos de alteração da olivina e da serpentina (Tab. 13A) mostra que o gel $\mathrm{Si}-\mathrm{Fe}$, resíduo da hidrólise da olivina, é sempre rico em $\mathrm{Ni}$ mas tem teores elevados em $\mathrm{Cr}$ e $\mathrm{Al}$ apenas nos horizontes mais evoluídos. Os produtos $\mathrm{Fe}-$ $\mathrm{Ni}$ de impregnação da serpentina são muito ricos em $\mathrm{Ni}$ e têm composição próxima à da hematita (em parte transformação magnetita-hematita?). A goethita possui $\mathrm{Al}, \mathrm{Cr}$ e Ni, e a hematita (LV), apenas os dois primeiros elementos.

A razão $\mathrm{Fe} / \mathrm{Si}$ (Tab. $13 B$ ) aumenta regularmente com a alteração, com a evolução da olivina e com a evolução dos géis Si-Fe: o mecanismo de alteração é de tipo laterítico.

A razão $\mathrm{Fe} / \mathrm{Ni}$ aumenta da rocha para a $L V$ e dos silicatos hipógenos para os óxidos ferruginosos (goethita, hematita), mas mostra valores mínimos no SG, na LA e nos produtos secundários, o que evidencia importação de Ni nesses materiais.

c) Distribuiçao do niquel A Tab. 14 fornece a distribuição do Ni nos diferentes minerais de cada horizonte, expressa em porcentagem do Ni total do horizonte. Fica claro que este elemento tem uma ligação predominante com os óxidos de $\mathrm{Fe}$ apenas na LV. Na LA, cerca de 

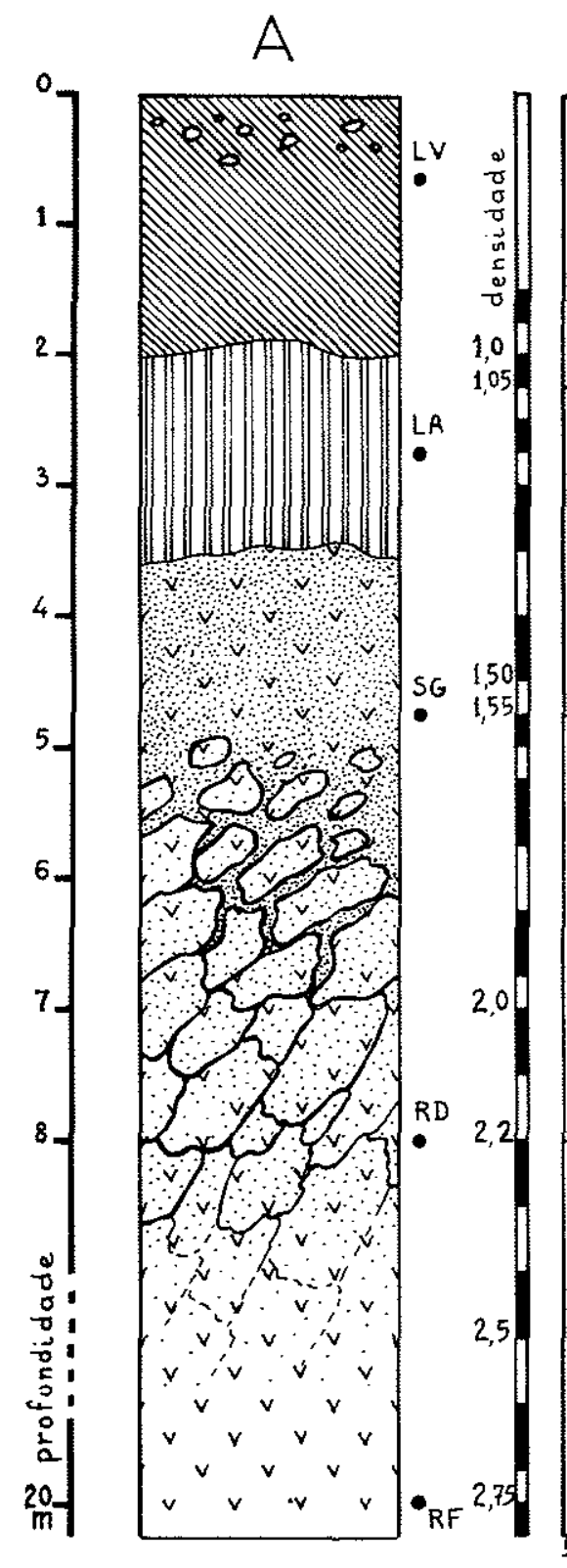

$9 \quad 876$

B

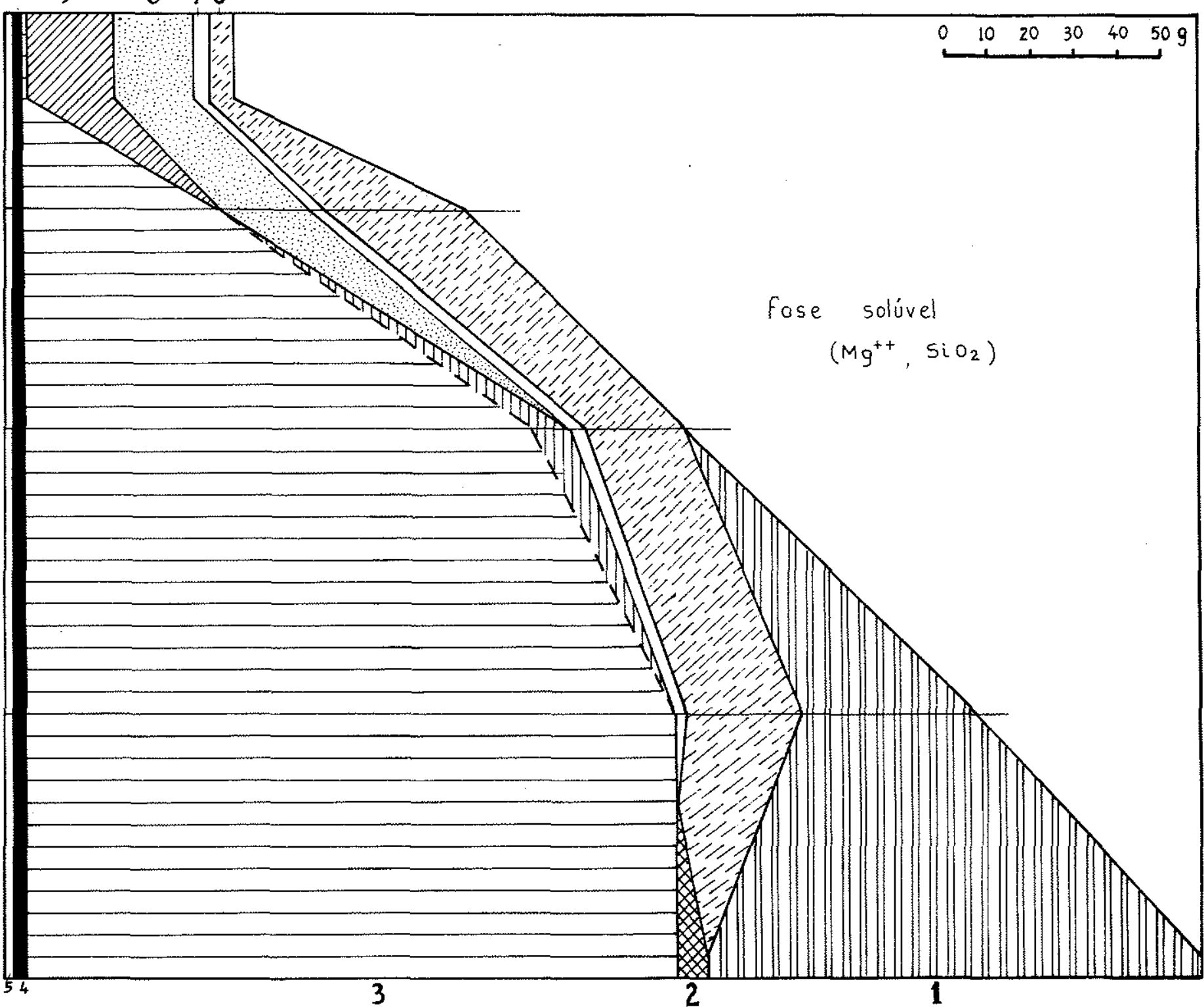

Figura $6-A$. Perfil de alteração na baixada. $B$. Evolução mineralógica quantitativa em função da alteração. 1. Olivina; 2 . carbonatos; 3. serpentina; 4. cromita; 5. vermiculita; 6. géis Si-Fe; 7. quartzo; 8. goethita; e 9. hematita 
Tabela $13-A$. Composição calculada dos produtos de alteração da olivina e da serpentina

\begin{tabular}{|c|c|c|c|c|c|c|c|}
\hline & & $\mathrm{H}_{2} \mathrm{O}$ & $\mathrm{SiO}_{2}$ & $\mathrm{Fe}_{2} \mathrm{O}_{3}$ & $\mathrm{Al}_{2} \mathrm{O}_{3}$ & $\mathrm{Cr}_{2} \mathrm{O}_{3}$ & $\mathrm{NiO}$ \\
\hline $\begin{array}{l}\text { Laterita } \\
\text { vermelha } \\
\text { Laterita } \\
\text { amarela }\end{array}$ & $\begin{array}{l}\text { Hematita } \\
\text { Goethita } \\
\text { Gel Si-Fe } \\
\text { Goethita } \\
\text { Gel Si-Fe }\end{array}$ & $\begin{array}{c}- \\
10,0 \\
9,0 \\
10,0 \\
9,70\end{array}$ & $\frac{\overline{-}}{15}$ & $\begin{array}{l}90,5 \\
78,1 \\
65,27 \\
79,68 \\
52,0\end{array}$ & $\begin{array}{l}3,1 \\
3,54 \\
2,94 \\
3,60 \\
2,34\end{array}$ & $\begin{array}{l}6,4 \\
6,69 \\
3,30 \\
3,99 \\
2,63\end{array}$ & $\begin{array}{l}\overline{1,87} \\
4,49 \\
2,72 \\
3,58\end{array}$ \\
\hline $\begin{array}{l}\text { Saprolito } \\
\text { grosso }\end{array}$ & $\begin{array}{l}\text { Fe-NI assoc. } \\
\text { c/serpent. } \\
\text { Gel Si-Fe }\end{array}$ & - & - & $\begin{array}{l}90 \\
35,9\end{array}$ & $\begin{array}{l}2 \\
0,85\end{array}$ & $\begin{array}{l}0,75 \\
0,31\end{array}$ & $\begin{array}{l}7,25 \\
1,98\end{array}$ \\
\hline Rocha dura & Gel Si-Fe & 26,2 & 38,53 & 33,62 & 0,64 & 0,07 & 0,94 \\
\hline
\end{tabular}

B. Razões $\mathrm{Fe} / \mathrm{Si}$ e $\mathrm{Fe} / \mathrm{Ni}$ nos horizontes, nos minerais hipógenos e nos produtos de alteração

\begin{tabular}{|c|c|c|c|c|c|c|c|c|}
\hline & $\mathrm{Fe} / \mathrm{Si}$ & $\mathrm{Fe} / \mathrm{Ni}$ & & $\mathrm{Fe} / \mathrm{Si}$ & $\mathrm{Fe} / \mathrm{Ni}$ & & $\mathrm{Fe} / \mathrm{Si}$ & $\mathrm{Fe} / \mathrm{Ni}$ \\
\hline $\begin{array}{l}\text { LV } \\
\text { LA }\end{array}$ & $\begin{array}{l}7,0 \\
1,12\end{array}$ & $\begin{array}{l}59,5 \\
20,0\end{array}$ & $\begin{array}{l}\text { Gel Si-Fe } \\
\text { Gel Si- }\end{array}$ & 4,35 & 14,5 & Goethita & - & 41,7 \\
\hline SG & 0,38 & 17 & $\begin{array}{l}\mathrm{Fe} \\
\text { Gel Si-Fe }\end{array}$ & $\begin{array}{l}1,75 \\
0,70\end{array}$ & $\begin{array}{l}14,5 \\
18\end{array}$ & & - & $\begin{array}{l}29,3 \\
12,4\end{array}$ \\
\hline $\begin{array}{l}\mathrm{RD} \\
\mathrm{R}\end{array}$ & $\begin{array}{l}0,28 \\
0,23\end{array}$ & $\begin{array}{l}35 \\
31\end{array}$ & $\begin{array}{l}\text { Gel Si-Fe } \\
\text { Olivina }\end{array}$ & $\begin{array}{l}0,87 \\
0,29\end{array}$ & $\begin{array}{l}35,8 \\
34\end{array}$ & $\begin{array}{l}\text { c/serpent. } \\
\text { Serpentina } \\
\text { Serpentina }\end{array}$ & $\begin{array}{l}0,17 \\
0,17\end{array}$ & $\begin{array}{l}26 \\
26\end{array}$ \\
\hline \multicolumn{3}{|c|}{ Amostra total } & \multicolumn{3}{|c|}{ ol. e prod. de alter. } & \multicolumn{3}{|c|}{ serp. e prod. de alt. } \\
\hline
\end{tabular}

Tabela 14 - Distribuição do níquel nos diferentes minerais em cada horizonte (em \% do níquel total do horizonte)

\begin{tabular}{c|c|c|c|c}
\hline & Olivina & $\begin{array}{c}\text { Serpentina } \\
(+ \text { prod.alter. })\end{array}$ & Gel Si-Fe & Goethita \\
\hline LV & - & - & 40 & 60 \\
LA & - & 6,6 & 62,4 & 30,9 \\
SG & - & 68,80 & 31,20 & - \\
RD & 17,50 & 51,25 & 31,25 & - \\
R & 47,50 & 51,25 & - & - \\
\hline
\end{tabular}

dois terços do Ni têm ligação silicatada, principalmente com o gel sílico-ferruginoso. No $\mathrm{SG}$, um terço do $\mathrm{Ni}$ pertence ao gel $\mathrm{Si}-\mathrm{Fe}$ e dois terços ocorrem sob forma oxidada, junto com o $\mathrm{Fe}$, adsorvidos nos defeitos do retículo da serpentina hipógena. Portanto, neste horizonte, a totalidade do Ni apresenta um ou outro tipo de ligação silicatada, embora fraca, como mostraram os ataques parciais.

Em Santa Fé, as formas de ocorrência do Ni na estrutura dos minerais (goethita e pimelita, Schellmann, 1978; e Kuhnel et al., 1978) não predominam.

\section{EVOLUCÃo GEOQUímica AO Nível DA PAISAGEM}

É nas áreas de baixada (87\% da área total do maciço, Fig. 2) que se encontram os perfis de alteração mais plenamente desenvolvidos. Mas, para completar o quadro geoquímico, é preciso também considerar a evolução dos outros setores da topossequência.

A. Alteração nos morrotes Muitas vezes, no topo dos morrotes, abaixo de uma delgada cobertura de LV, aflora rocha silicificada. Esta silicificação pode ser discreta, constando apenas de filoes de quartzo que preenchem diáclases da rocha pouco alterada (sobretudo no plano horizontal), associados ou não a veios de garnierita. Quando é mais intensa, chega a um verdadeiro silerete: a rocha transforma-se num boxwork de quartzo e calcedônia, preenchido e envolvido por material lateritico. A ausência de silicificação na rocha fresca e a correlação dos topos silicificados a uma mesma superfície (que corresponderia à superfície sul-americana) não deixam dúvida quanto à origem supérgena deste fenômeno.

A composição química de amostras de um perfil bem silicificado consta da Tab. 15A. A análise das fraçóes 
granulométricas indica que o quartzo e a calcedônia constituem um arcabouço (fração grosseira) preenchido por material saprolítico laterizado (fração fina). A composição desse material foi avaliada, recalculando os dados da análise química para $100 \%$, com exclusão da sílica. A Tab. 15B mostra que se trata de uma laterita bem evoluida $\left(70 \% \mathrm{Fe}_{2} \mathrm{O}_{3}\right)$.
O cálculo isovolume para as amostras deste perfil (Tab. 15C) evidencia a conservaçăo (e mesmo o ganho absoluto) da sílica no silcrete e a perda praticamente total do $\mathrm{Mg}$. A discrepância observada no comportamento do Fe é explicada pela Tab. 15D: na base do perfil, o ganho de Fe é devido à iluviação da goethita; nos horizontes superiores, as perdas de todos os componentes,

Tabela $15-A$. Composição química dos harizontes muito silicificados e alterados, no topo de um morro ( $\%$ em peso)

\begin{tabular}{c|l|c|c|c|c|c|c|c|c|c|c|c}
\hline $\begin{array}{l}\text { Pr. } \\
(\mathrm{m})\end{array}$ & & $\mathrm{PF}$ & $\mathrm{SiO}_{2}$ & $\mathrm{MgO}$ & $\mathrm{Fe}_{2} \mathrm{O}_{3}$ & $\mathrm{Al}_{2} \mathrm{O}_{3}$ & $\mathrm{Cr}_{2} \mathrm{O}_{3}$ & $\mathrm{NiO}$ & $\mathrm{CoO}$ & $\mathrm{CuO}$ & $\mathrm{MnO}_{2}$ & Total \\
\hline 0 & Am. tot. & 2,2 & 84,9 & 1,0 & 9,5 & 0,9 & 0,58 & 0,64 & 0,049 & 0,005 & 0,43 & 100,3 \\
2 & Am. tot. & 2,4 & 78,6 & 0,3 & 15,3 & 0,5 & 0,66 & 0,29 & 0,025 & 0,004 & 0,15 & 98,2 \\
& $\emptyset>250 \mu$ & 3,0 & 73,9 & 0,5 & 20,2 & 0,7 & 0,33 & 0,37 & 0,100 & 0,007 & 0,37 & 100,1 \\
6 & $250 \mu \mid \varnothing>$ & & & & & & & & & & & \\
& $62 \mu$ & 6,1 & 43,4 & 1,0 & 41,7 & 3,6 & 2,38 & 0,78 & 0,050 & 0,046 & 0,26 & 99,3 \\
& $\emptyset<62 \mu$ & 6,8 & 28,4 & 1,2 & 51,7 & 3,6 & 3,66 & 0,81 & 0,067 & 0,021 & 0,32 & 96,5 \\
9 & Am. tot. & 5,1 & 56,4 & 0,7 & 34,7 & 1,6 & 1,23 & 0,73 & 0,081 & 0,009 & 0,38 & 100,9 \\
\hline
\end{tabular}

B. Composição recalculada da fração não silicosa dessas amostras

\begin{tabular}{l|l|c|c|c}
\hline $\begin{array}{l}\text { Prof. } \\
(\mathrm{m})\end{array}$ & & $\mathrm{Fe}_{2} \mathrm{O}_{3}$ & $\mathrm{MgO}$ & $\mathrm{NiO}$ \\
\hline $0^{*}$ & Am. tot. & 63 & 6,6 & 4,2 \\
2 & Am. tot. & 72 & 1,4 & 1,4 \\
& $\emptyset>250 \mu$ & 77 & 1,9 & 1,4 \\
6 & $250 \mu>\emptyset>62 \mu$ & 74 & 1,8 & 1,4 \\
& $\emptyset<62 \mu$ & 72 & 1,7 & 1,1 \\
9 & Am. tot. & 79 & 1,6 & 1,6 \\
\hline
\end{tabular}

C. Balanço: ganhos e perdas em proporção das quantidades iniciais e óxidos na amostra (em \%)

\begin{tabular}{|c|c|c|c|}
\hline $\begin{array}{l}\text { Prof. } \\
\text { (m) }\end{array}$ & $\mathrm{SiO}_{2}$ & $\mathrm{MgO}$ & $\mathrm{Fe}_{2} \mathrm{O}_{3}$ \\
\hline $\begin{array}{l}0 \\
2 \\
9\end{array}$ & $\begin{array}{l}+48 \\
+1 \\
+1\end{array}$ & $\begin{array}{l}-99 \\
-100 \\
-99\end{array}$ & $\begin{array}{l}-26 \\
-13 \\
+183\end{array}$ \\
\hline
\end{tabular}

salvo a sílica, na mesma proporção (cerca de dois terços), refletem o esvaziamento mecânico das cavidades do boxwork silicoso de seu conteúdo laterítico.

Assim, o estudo dos perfis de alteração dos topos dos morrotes sugere que nesses sítios as rochas evoluíram pelas etapas seguintes:

- Silicificação da rocha pouco alterada e conseqüente formação de um denso reticulado de quartzo e calcedônia.

- Alteração laterítica levando à evolução dos núcleos rochosos em LV.

- Esvaziamento mecânico das cavidades do boxwork na parte superior do perfil e iluviação do material laterítico para a base do perfil.

$B$. Perdas e ganhos na topossequência. Integração dos dados ao nivel da paisagem Integrando os dados relativos aos perfis de topo pouco desenvolvidos e os perfis lateríticos das baixadas (Tab. 16), conclui-se que o $\mathrm{Mg}$ e o Si são evacuados para fora do maciço à medida que a alteração prossegue. Apenas os topos de alguns morrotes indicam retenção ou acumulação de Si (Tab. $15 C$ ).

$\mathrm{O} \mathrm{Fe}, \mathrm{Cr}$ e Al comportam-se sempre de maneira estritamente residual. Pode haver um certo deslocamento mecânico desses elementos por iluviação em direção aos

$D$. Balanço das perdas na amostra de profundidade de $2 \mathrm{~m}$ em relação à amostra de profundidade de $9 \mathrm{~m}$ ( $\%$ da quantidade de $6 x i-$ dos na am. profunda)

\begin{tabular}{c|c|c|c|c|c|c|c|c|c}
\hline $\mathrm{H}_{2} \mathrm{O}$ & $\mathrm{SiO}_{2}$ & $\mathrm{MgO}$ & $\mathrm{Fe}_{2} \mathrm{O}_{3}$ & $\mathrm{Al}_{2} \mathrm{O}_{3}$ & $\mathrm{Cr}_{2} \mathrm{O}_{3}$ & $\mathrm{NiO}$ & $\mathrm{CoO}$ & $\mathrm{CuO}$ & $\mathrm{MnO}_{2}$ \\
\hline-67 & -2 & -70 & -69 & -80 & -63 & -72 & -75 & -69 & -72 \\
\hline
\end{tabular}


Tabela 16 - Balanço geoquímico por setor da topossequência ( $\%$ da quantidade inicial de óxido na rocha)

A. Magnésio

\begin{tabular}{l|c|c|c|c}
\hline & Topo & Encosta & Sopé & Baixada \\
\hline LV & n.d. & n.d. & n.d. & -99 \\
LA & - & -78 & -86 & -84 \\
SG & -59 & -60 & -59 & -66 \\
RD & -34 & -39 & -39 & -40 \\
\hline
\end{tabular}

\section{B. Sílica}

\begin{tabular}{l|c|c|c|c}
\hline & Topo* & Encosta & Sopé & Baixada \\
\hline LV & n.d. & n.d. & n.d. & -95 \\
LA & - & -68 & -72 & -71 \\
SG & -35 & -44 & -39 & -44 \\
RD & -15 & -23 & -19 & -27 \\
\hline
\end{tabular}

C. Níquel

\begin{tabular}{c|c|c|c|c}
\hline $\begin{array}{c}\text { Densidade } \\
\text { aparente }\end{array}$ & Topo** & Encosta & Sopé & Baixada \\
\hline LV & n.d. & n.d. & n.d. & -24 \\
$0,6-1,0$ & - & +133 & +70 & +314 \\
$1,1-1,5$ & -22 & +11 & $+155^{i}$ & +436 \\
$1,6-2,0$ & -22 & +6 & -9 & +373 \\
$2,1-2,7$ & +9 & +8 & +2 & +45 \\
\hline
\end{tabular}

* Excluindo o silcrete

** Excluindo os veios de garnierita

- Não foi amostrado

n.d. Não determinado

horizontes inferiores do perfil. Apesar disso, a espessa $\mathrm{LV}$ das baixadas mostra um excedente de $\mathrm{Fe}, \mathrm{Cr}$ e $\mathrm{Al} \mathrm{em}$ termos absolutos (Tab. 3).

$\mathrm{O}$ balanço do $\mathrm{Ni}$ é fracamente negativo apenas no topo, quando o cálculo é feito excluindo os veios de garnierita, e fortemente positivo nos demais niveis, principalmente na baixada. O leve déficit de Ni encontrado na LV do topo não basta para compensar o excedente, que se verifica por toda a paisagem, em relação a uma acumulação puramente residual.

Assim, a paisagem ultramáfica de Santa Fé apresenta uma distribuição paradoxal dos elementos: solúveis concentrados a montante $(\mathrm{Si})$ e residuais $(\mathrm{Fe}, \mathrm{Cr}, \mathrm{Al})$ a jusante. Isso é contrário à lógica da distribuição dos elementos na paisagem (Polynov, 1956), comparada por Tardy (1969) a um processo cromatográfico. Outro problema a ser esclarecido é a ausência de fontes para as acumulações absolutas. Todas essas anomalias podem ser compreendidas levando em consideração a dimensão temporal do processo de alteração.

A evolução laterítica do boxwork silicoso e a alteração prevalecente nas baixadas estão em equilíbrio com as condições climáticas atuais, que não favorece neoformaçð̃es sílico-magnesianas nem silicificação. A estrita associação dos horizontes silicificados com os testemunhos da antiga superfície sul-americana leva à hipótese de que este fenômeno foi contemporâneo daquela superfície. Antigas silicificaçőes são também descritas em outro maciços ultramáficos brasileiros (Santos, 1974; Trescases e Olivieira, 1978; e Melfi, 1979). A LV acumulada nas baixadas não pode resultar apenas da evolução última da LA subjacente mas deve ser, em parte, produto da erosão dos antigos perfis de topo (superfície sul-americana) depositados nas áreas mais baixas.

\section{CONCLUSÕES}

A. Interpretação geoquímica espaço-temporal e gênese da jazida A intrusão ultramáfico-alcalina de Santa Fé, relacionada à reativação wealdeniana (K sup.), depois de parcialmente serpentinizada, foi exumada por ocasião da peneplanização generalizada ocorrida no continente (fase de agradação do ciclo erosional sulamericano, no Terciário Inferior).

A seqüência de mecanismos supérgenos que ocorreram desde então é resumida a seguir.

Durante um período de certa estabilidade, no Terciário Inferior e Médio, quando o relevo já estava bem aplainado, e em condições de clima seco a semi-árido, o intemperismo conduziu à formação de uma cobertura de alteração não-laterítica, com intensa silicifiçação na base dos perfis sobre dunito, na forma de um boxwork silicoso envolvendo núcleos de rocha pouco alterada.

Posteriormente, sob clima mais úmido, ocorreu laterização generalizada, com concentração residual do $\mathrm{Ni}$, $\mathrm{Fe}, \mathrm{Cr}, \mathrm{Al}$ etc., evacuação intensa do $\mathrm{Si}$ e $\mathrm{Mg}$ da rocha ultramáfica alterada e conservação da malha silicosa do boxwork.

Um novo levantamento do continente por arqueamento, no Terciário Superior, trouxe como conseqủência a retomada da erosão (ciclo Velhas). A superfície sul-americana foi sendo desmantelada e entalhada mais profundamente onde a silicificação era menos intensa ou inexistente, resultando na emergência de relevos sustentados pela camada de silica (silcrete). No Quaternário Inferior, a fase de agradação do ciclo VeIhas elaborou uma nova superfície de aplainamento (baixada atual). Nessa fase, nos testemunhos de superfície sul-americana (morros), uma parte do Ni concentrado residualmente nos antigos perfis de alteração migrou em solução, verticalmente para baixo, dando os veios de garnierita nas fraturas e no boxwork silicoso; uma parte migrou também em solução, lateralmente, em direção aos novos perfis lateríticos que começaram a se desenvolver na baixada.

Mas pouco a pouco, até hoje, toda a cobertura laterítica ( $\mathrm{Fe}, \mathrm{Cr}, \mathrm{Al}, \mathrm{Ni}$ ) desses testemunhos foi erodida e deslocada mecanicamente para a baixada, só ficando nos morrotes a rocha pouco alterada, eventualmente com alguns veios de garnierita, um pouco de $L V$ e, de vez em quando, o antigo silcrete mais ou menos esvaziado. Na baixada, pelo contrário, a alteração laterítica recente aprofunda cada vez mais os perfis. Nestes, a alteração começa pela dissolução da olivina que abandona 
um residuo amorfo sílico-ferruginoso-niquelífero; a serpentina resiste à hidrólise e fixa em suas clivagens e defeitos uma parte do $\mathrm{Fe}$ e do $\mathrm{Ni}$, insolúveis sob forma de hidróxido, devido às condiçðes alcalinas de pH (RD e SG pro parte). Depois (SG pro parte e principalmente $\mathrm{L} A$ ), a serpentina também é dissolvida, os géis $\mathrm{Si}-\mathrm{Fe}-\mathrm{Ni}$ são parcialmente dessicificados, a cromita é progressivamente corroída e todos os hidróxidos residuais começam a cristalizar em goethita aluminosa, cromífera e niquelífera. No fim (LV), a estrutura da rocha é destruída, uma parte do Ni é levemente lixiviada para baixo em direção à LA e a goethita é parcialmente desidratada em hematita. A toda essa evolução in situ das baixadas vêm-se juntar o aporte lateral do $\mathrm{Ni}$ dissolvido dos relevos (do início do desmantelamento da superfície sulamericana até hoje) e o aporte lateral mecânico de material laterítico ( $\mathrm{Fe}, \mathrm{Al}, \mathrm{Cr}, \mathrm{Ni} . .$. ) erodido dos antigos perfis sul-americanos. O esquema geoquímico global (espacial e temporal) da jazida de Santa Fé consta da Fig. 7. $\mathrm{O}$ comportamento levemente solúvel do $\mathrm{Ni}$ deve ter como conseqüência uma certa evacuação desse elemento dos perfis atuais das baixadas em direção à orla piroxenítica do maciço e às encaixantes.
B. A jazida de Santa Fé comparada com outras jazidas lateriticas de níquel do mundo A comparaçåo da jazida de Santa Fé com as outras jazidas de Ni do Brasil (Pecora e Barbosa, 1944; Andrade e Botelho, 1974; e Melfi et al., 1979) mostra que sua gênese e características são comparáveis às das demais. Apenas pode ser diferenciada a evolução recente (pós-Velhas) no domínio semi-árido do nordeste (jazida de São João do Piauí, onde esta evolução não é mais a laterização mas a esmectitização), e pode ser notado, no caso de Santa Fé, um grau mais adiantado de desmantelamento da superfície sul-americana e, talvez, de laterização na superfície Velhas.

As características principais das jazidas de Ni laterítico do Brasil podem ser assim resumidas:

- Correlação com dois ciclos de aplainamento: Terciário Inferior a Médio e Terciário Superior-Quaternário.

- Silicificação (antiga) nos relevos.

- Laterização nas baixadas mas ainda limitada (quando não ausente como no nordeste).

- Tamanhos è teores médios, ora por causa de um clima não mais suficientemente agressivo (nordeste),

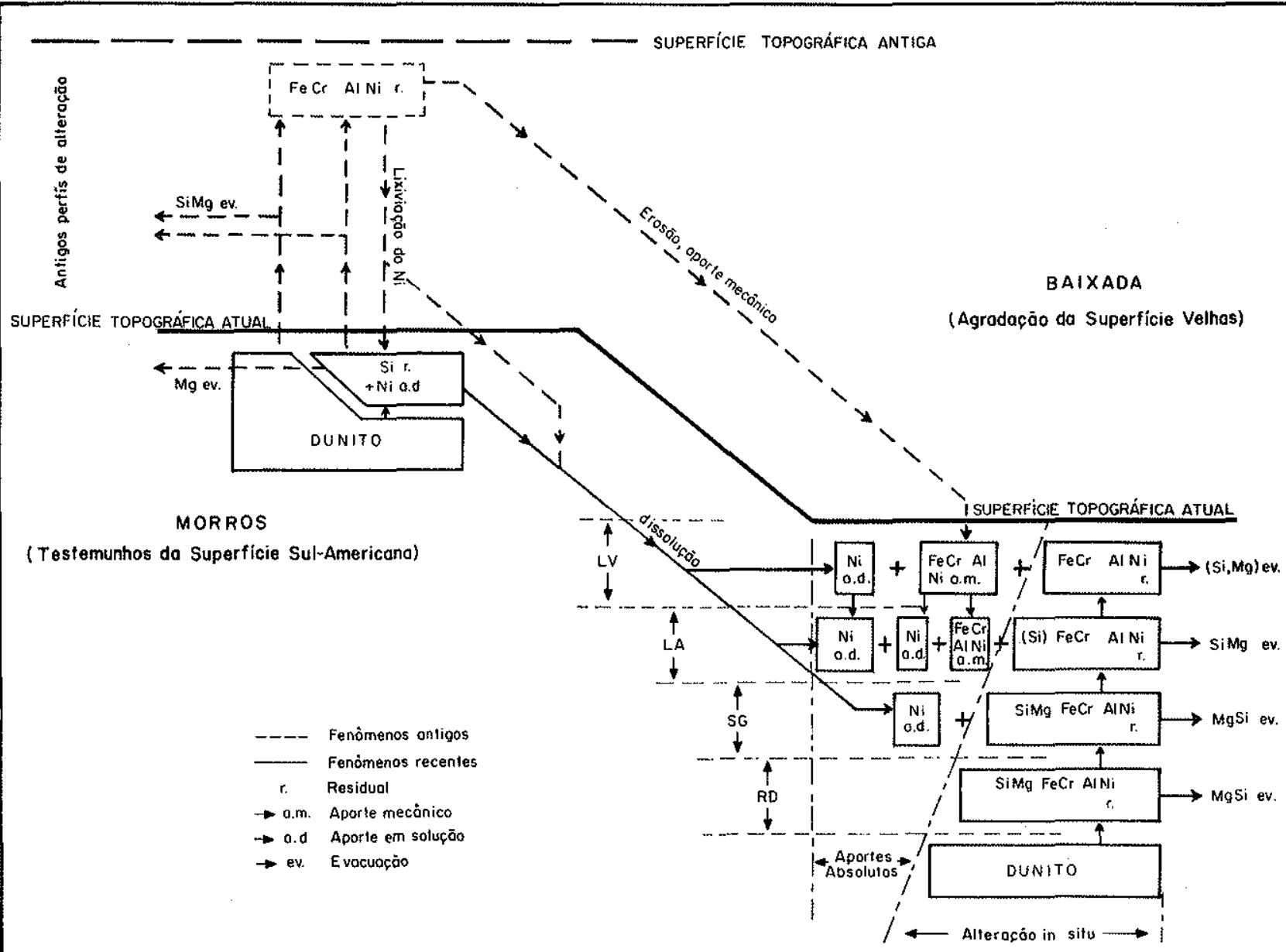

Figura 7 - Esquema geoquímico da jazida de Santa Fé 
ora por causa da pouca duração do processo recente de laterização (Goiás).

- Acumulação preferencial do $\mathrm{Ni}$ nas baixadas.

- Acumulação preferencial do Ni na parte média dos perfis de alteração.

- Predominância dos minérios de tipo silicatado sobre os tipos oxidados.

As principais jazidas do mundo (De Vletter, 1955; Bonifas, 1959; Jukovic, 1963; Santos-Ynigo, 1964; Hotz, 1964; Trescases, 1975; e Lelong et al., 1976) mostram também correlação com ciclos de aplainamentos terciários ou terciário-quaternários. Mas, à exceção das jazidas ou ocorrências descritas na Austrália (Zeissink, 1969) ou na África do Sul (De Waal, 1971), as outras não mostram silicificaçð̃es tão desenvolvidas como aqui; nelas, a localização do Ni é diferente ao nível da paisagem (as zonas altas são melhores), ao nível dos perfis de alteração (a base é, em geral, mais enriquecida) e ao nível do minério (o tipo oxidado predomina na maioria das lateritas niquelíferas). É interessante notar a estrita localização no hemisfério sul do que poderia ser chamado de "Tipo Brasileiro" de laterita niquelifera.

Nota Este artigo é, em parte, o resumo de alguns capítulos a tese de doutoramento apresentada ao Instituto de Geociências da USP por Sônia Maria Barros de Oliveira em março de 1980.

\section{BIBLIOGRAFIA}

ANDRADE, M. R. e BOTELHO, L. C. - 1974 - Perfil analitico do Niquel. Bol. DNPM-33, Rio de Janeiro, 90 pp.

BARBOUR A.P. - 1976 - Geologia do maciço ultramáfico de Santa Fé (GO), Tese de Livre-Docência IG-USP, 138 pp.

BARBOUR, A. P.; GIRARDI, V.A.V.; KAWASHITA, K.; e SOUZA, A.M.S. de - $1979-$ Geocronologia do complexo máfico-ultramáfico alcalino de Santa Fé, Goiás. Bòl. IG-USP 10: 11-18.

BONIFAS, M. - 1959 - Contribution à l'étude géochimique de l'altération la téritique. Mem. Cart. Geol. Als. Lorr., Strasbourg 17, 159 pp.

BRAUN, O.P.G. - 1970 - Contribuiçăo à Geomor fologia do Brasil Central. Rev. Bras. Geogr. ano XXXIl 3: 3-40.

BRINDLEY, G. W. e HANG, P.T. - 1973 - The nature of garnierites -1 Structures', chemical composition and color characteristics. Clay and Clay Min. 21: $27-40$

BRINDLEY, G, W. E MAKSIMOVIC, Z. -1974 - The nature and nomenclature of hydrous Ni-containing silicates, Clay minerals 10: 271-277.

DE VLETTER, D. R - 1955 - How Cuban ore was formed: a lesson in lateritic genesis. Eng. and Min. Journal 156 (10): 84-87

DE WAAL, S. A. - 1971 - South African nickeliferous serpentinites. Miner. Sc. Engeneering, Pretoria 3 (2): 32-45.

HOTZ, P. E - 1964 - Nickeliferous laterites in Southwestern Oregon and Northwestern California. Ec. Geology 59 (3): 335-396.

JURKOVIC, I. -1963 - Some geochemical aspects about the genesis of the nickel deposit Loma de Hierro (Venezuela). Geoloski Vjesnik 17: 103-112.

KING, L.C. - 1956 - A geomorfologia do Brasil Oriental, m Rev, Br, Geogr. 2: $147-265$

KUHNEL, R. A.; ROORDA, H. J.; e STEENSMA, J. J. S. - 1978 - Distribution and partitioning of elements in nickeliferous laterites. Bull. BRGM sec. II, 3: 191-206.

LELONG, F ; TARDY, Y ; GRANDIN, G.; TRESCASES, J J; e BOULANGE, B. - 1976 - Pedogenesis, chemical weathering and processes of formation of some supergene ore deposits. In Handbook of strata-bound and stratiform deposits, R. H. Wolf (ed.), Elsevier, Amsterdã, 3: 93-173.

LESSA S:, M.; ANDRADE, R.S. de e BERBERT, C.O. - 1971 - Projeto Jussara - Geologia das quadriculas de Britânica, Santa Fé, Araguapaz e Jussara, Estado de Goiás. DNPM (Executado pela CPRM), Goiânia (inédito).

MELFI, A. J.; TRESCASES, J.J.; e OLIVEIRA, S. M. B. de - 1979 - Les laterites nickélifères du Brésil. Apresentado no Int. Sem. on Lat. Processes. Trivandrum, fndia. Cah. ORSTOM sér. Geol. (no prelo).

MILLOT, G. e BONIFAS, M. - 1955 - Transformation isovolumétrique dans les phénomènes de latérisation et de bauxitisation. Bull. Serv. Cart. Geol. Als. Lorr. 8 (1): 3-20.
OLIVEIRA, S. M. B. de e MELFI, A. J. - 1979 - Consideraçőes sobre a origem das esmectitas nos níveis de alteração dos piroxenitos de Santa $\mathrm{Fé}(\mathrm{GO})$ Bol, 1G-USP 10: 91-96.

OLIVEIRA, S. M. B. de - 1980 - Alteração ìntempérica das rochas ultrabásicas de Santa Fé (GO) e gênese do depósito niquelifero. Tese de Doutoramento apresentada ao IG-USP, $216 \mathrm{pp}$.

PECORA, W. T e BARBOSA, A. L. M. - 1944 - Jazida de níquel e cobalto de São José do Tocantins, Estado de Goiás. Bol. DNPM-DFPM 64, 69 pp.

POLYNOV, B. B. - 1956 - Geochemical landscapes (em russo), Selected papers, Akad. Nank SSSR.

SANTOS, J. F. dos - 1974 - Fatores de controle na concentração do niquel lateritico condicionado pela evoluçăo geológica e geomorfológica do complexo básico-ultrabásico de São Joăo do Piaú (PI). An. XXVIII Congr. Br. Geol. 6: 25-32.

SANTOS, Y. L. - 1964 - Distribution of iron, alumina and silica in Puja, da Laterite of Mati, Davao Province, Mindanao - Island (Philippines) XXII Int. Geol, Congress New Delhi, sect. 14: 126-141.

SCHELLMANN, W. - 1978 - Behavior of nicked, cobalt and chromium in ferruginous lateritic nickel ores. Bull. BRGM, sect. II, 3: 275-282.

SEGALEN, P. - 1968 - Note sur une méthode de détermination de produits minéraux amorphes dans certains sols à hydroxydes tropicaus. Cah. ORSTOM, sér. Péd., 6 (1): 105-125.

SOUZA, A. M. S. de - 1978 - Mineralogia e petrologia do complexo ultramáfico e alcalino de Santa Fé, Goiás. Tese de Mestrado, Univ. Fed. do Pará, 122 pp.

TARDY, Y -1969 m. Géochimie des altérations. Etude des arènes et des eaux de quelques massifs cristallins d'Europe et d'Afrique. Mem. Serv. Cart. Geol. Als e Lorr 31, $199 \mathrm{pp}$.

TRESCASES, J. J. - 1975 - L'evolution géochimique supergène des roches ultrabasiques en zone tropicale. Formation de gisements nickèliferes de Nouvelle-calédonie. Mem. ORSTOM 78, 259 pp., Paris.

TRESCASES, J. J. e OLIVEIRA, S. M. B. de - 1978 - Alteração dos serpentinitos de Morro do Níquel (MG). An. XXX Congr. Br. Geol. 4: 1655-1669.

TRESCASES, J. J. - 1979 - Remplacement progressif des silicates par les hydroxydes de fer et de nickel dans les profils d'altération tropicale des roches ultrabasiques. Accumulation résiduelle et Epigénie. Sciences Géologiques, Estrasburgo (no prelo):

ZEISSINK, H. E. - 1969 - The mineralogy and geochemistry of a nickeliferous laterite profile (Greenvale, Queensland, Australia). Miner. Deposita 4 (2): 132-152. 